Article

\title{
Morphological Features-Based Descriptive Index System for Lunar Impact Craters
}

\author{
Min Chen 1,2,3, Mengling Lei 1,2,3,*, Danyang Liu 1,2,3, Yi Zhou ${ }^{4}$, Hao Zhao ${ }^{4}$ and Kejian Qian 5 \\ 1 Key Lab of Virtual Geographic Environment, Ministry of Education of PRC, Nanjing Normal University, \\ Nanjing 210023, China; chenmin0902@163.com (M.C.); liudanyangsno@163.com (D.L.) \\ 2 State Key Laboratory Cultivation Base of Geographical Environment Evolution (Jiangsu Province), \\ Nanjing 210023, China \\ 3 Jiangsu Center for Collaborative Innovation in Geographical Information Resource Development and \\ Application, Nanjing 210023, China \\ 4 School of Geography and Tourism, Shaanxi Normal University, Xi'an 710062, China; \\ zhouyilucky@snnu.edu.cn (Y.Z.); zhaohao@snnu.edu.cn (H.Z.) \\ 5 Superengine Graphics Software Technology Development Co. Ltd., Suzhou 215000, China; \\ qiankejian@superengine.com.cn \\ * Correspondence: menglinglei918@126.com; Tel.: +86-156-5102-8110
}

Received: 9 November 2017; Accepted: 22 December 2017; Published: 29 December 2017

\begin{abstract}
Lunar impact craters are important for studying lunar surface morphology because they are the most typical morphological units of the Moon. Impact crater descriptive indices can be used to describe morphological features and thus provide direct evidence for both the current state and evolution history of the Moon. Current description methods for lunar impact craters are predominantly qualitative, and mostly focus on their morphological profiles. Less attention is paid to the detailed morphological features inside and outside of the craters. A well-established and descriptive index system is required to describe the real morphological features of lunar impact craters, which are complex in a systematic way, and further improve study, such as heterogeneity analyses of lunar impact craters. This study employs a detailed lunar surface morphological analysis to propose a descriptive index system for lunar impact craters, including indices for the description of individual craters based on their morphological characteristics, spatial structures and basic composition (i.e., crater rim, crater wall, crater floor, central uplift, and ejecta), and indices for crater groups, including spatial distribution and statistical characteristics. Based on the proposed descriptive index system, a description standard for lunar impact craters is designed for categorising and describing these indices in a structured manner. To test their usability and effectiveness, lunar impact craters from different locations are manually detected, and corresponding values for different indices are extracted and organised for a heterogeneity analysis. The results demonstrate that the proposed index system can effectively depict the basic morphological features and spatial characteristics of lunar impact craters.
\end{abstract}

Keywords: lunar impact craters; morphological features; descriptive index system

\section{Introduction}

The Moon is the most important natural satellite and the closest celestial body to Earth. Because of its unique position and potential abundant resources, the Moon has become an important research subject for understanding the origin and evolution of the Earth-Moon system and the Solar System [1]. Studies of lunar morphology have long been a fundamental aspect of lunar exploration [2], as the morphological characteristics of the lunar surface can not only directly reflect the current state of the Moon, but also record information which reveal the formation and evolution history of the Moon [3]. 
Magma movement inside the Moon ended during the large-scale formation of lunar maria, and the contribution of other exogenetic processes to lunar morphology is relatively insignificant; this has led researchers to believe that the lunar surface morphology has been shaped predominantly by high-speed impacts from external celestial bodies (e.g., [4,5]). All these findings on lunar morphology provide insight for scientific topics such as exploration of the origin of the Moon and its evolution history.

Among various lunar morphological features, lunar impact craters are one of the most important geological tectonic units [6]. Due to fewer external forces on the Moon (e.g., wind and water), many craters are well preserved [7]. As the most typical morphological units on the Moon, lunar impact craters provide major insight into lunar surface morphology and its forms, structures, and feature distribution $[8,9]$. In-depth studies on the morphology, classification and evolution of these craters are important for a greater understanding of the Moon, including the geological age of the lunar surface, the development and evolution patterns of lunar morphology, the thickness of the lunar regolith, and optimal locations for soft landing of probes [10]. Through investigating lunar craters and their morphological features, descriptive index systems can be designed and employed for a better interpretation of these craters. The establishment of such a system could improve the scientific classification scheme for lunar craters, and further facilitate studies on lunar crater identification, spatial heterogeneity analysis of lunar crater morphology, etc.

In 2012, the International Astronomical Union (IAU) published names and associated descriptions of almost 8600 lunar craters on the United States Geological Survey's (USGS) official website. The descriptions include the naming date, the etymology, the coordinates of the crater centre, and the diameter of the crater [11]. There are also numerous studies conducted directly on lunar craters, focusing on their type and structure, detection and identification, spatial heterogeneity, formation mechanisms, and evolution processes. On one hand, several classification systems have been proposed to differentiate between craters, laying a preliminary foundation for crater description. First, the shape of impact craters was employed for classification. For example, Oberbeck and Quaide [12] proposed the Oberbeck \& Quaide classification where they categorised craters into four types, referred to as simple bowl-shaped, uplifted, flat-based, and concentric; Stöffler et al. [13] divided craters into three groups, including complex craters, simple craters, and impact basins; and He et al. [14] concluded seven crater types, called simple, bowl-shaped, flat-based, central uplifted, concentric, complex, and lunar mare remnant. Second, other morphological features were introduced to the classification of lunar impact craters. Baldwin [15] categorised craters into five classes according to the clarity of crater boundaries, from clearly visible craters to barely visible ones; Fieder [16] proposed his G.Fieder classification scheme and described 13 types of craters and 23 types of ring structures based on geological characteristics; and the Nakano classification [17] used spatial patterns and crater scale to determine seven primary and 13 atypical types of lunar impact craters. Wood and Anderson [18] considered both morphology and morphometry when they proposed the Wood \& Anderson classification, which involved 18 types of craters according to differences in crater margin profiles, inner crater wall structure, and crater floor features; these were further divided into five groups based on the degree of erosion [18]. Finally, Heiken et al. [6] proposed three classes according to crater diameter and development, including simple bowl-shaped craters, relatively large, still developing craters with central peaks, and giant ancient craters in which central peaks were converted into multi-ring basins.

On the other hand, many previous studies have analysed specific morphological features of lunar impact craters directly, which can be represented by independent indices, such as size and scale (e.g., [19-21]), crater shape (e.g., [22-25]), depth-to-diameter ratio (e.g., [26-29]), form of the ejecta layer (e.g., [30-33]), and the morphological relationships between different craters (e.g., [34-36]), to provide critical information for intuitive recognition of lunar craters. Based on these morphological features, further research on lunar crater formation and chronology has also been conducted. For example, Florensky et al. [37] argued that there should be a correlation between the structure and size of impact craters and, based on this assumption, the temporal and spatial sequences of crater formation were analysed; Head III et al. [38] revealed the formation processes of craters through their temporal and 
spatial distributions; Michael and Neukum [39] attempted to derive ages for lunar surfaces using a crater size-frequency distribution; and Zhao et al. [40] studied the formation ages of lunar craters in Sinus Iridum using their diameter and frequency distribution. Moreover, Bart [41] argued that radiation patterns and the overlapping relationships of impact craters can be used to deduce the relative age of craters, and attempted heterogeneity analyses on crater morphology and gravel deposition based on this hypothesis [42].

In summary, there are a considerable number of studies on the morphological features of lunar impact craters and their related descriptive indices. However, some areas require further investigation, detailed as follows:

(1) Although there are several classification schemes for lunar impact craters, there is no common and standardised index system that can group different craters according to their morphological features. Currently, morphological descriptions are predominantly qualitative, and standardised, quantitative descriptive indices are rarely used, resulting in rather subjective crater classification.

(2) Restricted by the complexity of crater morphology and structure, the diversity of crater types and experimental methods and data, current research mainly focuses on describing the shape and profile of lunar craters. There are relatively few descriptions focusing on detailed morphological features (for example, the number of central peaks and ejecta).

(3) Current descriptive methods are mainly written in an unstructured manner. Further study on how to organise and present this information in a structured way, and thus enhance the applicability in different research cases, is required.

According to incomplete statistics, there are more than 33,000 impact craters on the Moon's surface [2]. Descriptive indices of the morphological features of these craters should be refined for better interpretations of lunar craters (e.g., [43,44]) and further refined for other related studies, such as heterogeneity analyses, and surface and feature dating. Hence, this study proposes a morphological features-based descriptive index system for lunar impact craters, as well as a structured description standard. Based on an analysis and summary of lunar impact crater morphological characteristics, Section 2 proposes a descriptive index system for both individual craters and crater groups. Section 3 presents a descriptive index structure with the aim of enhancing its applicability, before introducing the description standard. Using a heterogeneity analysis as an example in Section 4, we manually detect lunar impact craters in different areas and compare corresponding values for different indices. The conclusions and future implications are presented in Section 5.

\section{Morphological Analysis and Descriptive Index System of Lunar Impact Craters}

The lunar crater impact process controls their resulting morphological characteristics [45]. Using the impact mechanism of lunar craters, we examine the formation of basic crater features and their characteristics. Accordingly, a lunar crater descriptive index system is designed for both individual crater and crater groups. Methods for the quantitative calculation of indices are provided.

\subsection{Descriptive Indices for Individual Craters}

Lunar impact crater forms are complex and diverse due to different impact processes and sequences. Crater identification is the first step in morphology analyses, and boundaries must be determined before indices extraction and calculation. Typically, an individual impact crater can be defined as a simple crater, which is more or less bowl-shaped, while a complex crater normally has a central peak, terraces, and internal rings [46]. In this study, the first step is to design descriptive indices for individual craters, including the basic geometry, crater rim, crater wall, crater floor, central uplift, and ejecta. All indices are computed under a normal equal-area, pseudo-cylindrical projection (the Mollweide projection). 


\subsubsection{Basic Geometry and Corresponding Indices}

Individual lunar impact craters are typically circular depression structures and are widely found on the surface of the Moon. They are formed by random impacts of high-speed meteoroids, followed by vigorous excavation of surface soil. The formation process can be mainly divided into three stages: compression and excavation, morphological change, and, finally, shape formation (shown in Figure 1). During impact, the meteoroid penetrates the ground surface to a depth several times its radius, and shock compression waves together with rarefaction waves lead to immediate excavation and crater formation. Shock compression waves firstly cause vigorous compression of rocks near the point of impact, immediately after which the rocks enter a re-shaping stage, which is largely related to rarefaction waves. The release of pressure causes the upward and outward projection of a large amount of debris. This is accompanied by the formation of a transient crater, the depth of which reaches the maximum crater depth. Subsequently, another stage of re-shaping begins. This stage is associated with gravity, rock mechanics, crater size, and other factors [47]. Some debris thrown upwards fall back into the crater, and some loose debris deposited at the crater edge slide back or collapse into the crater under gravity. The crater is finally formed when it becomes relatively stable.

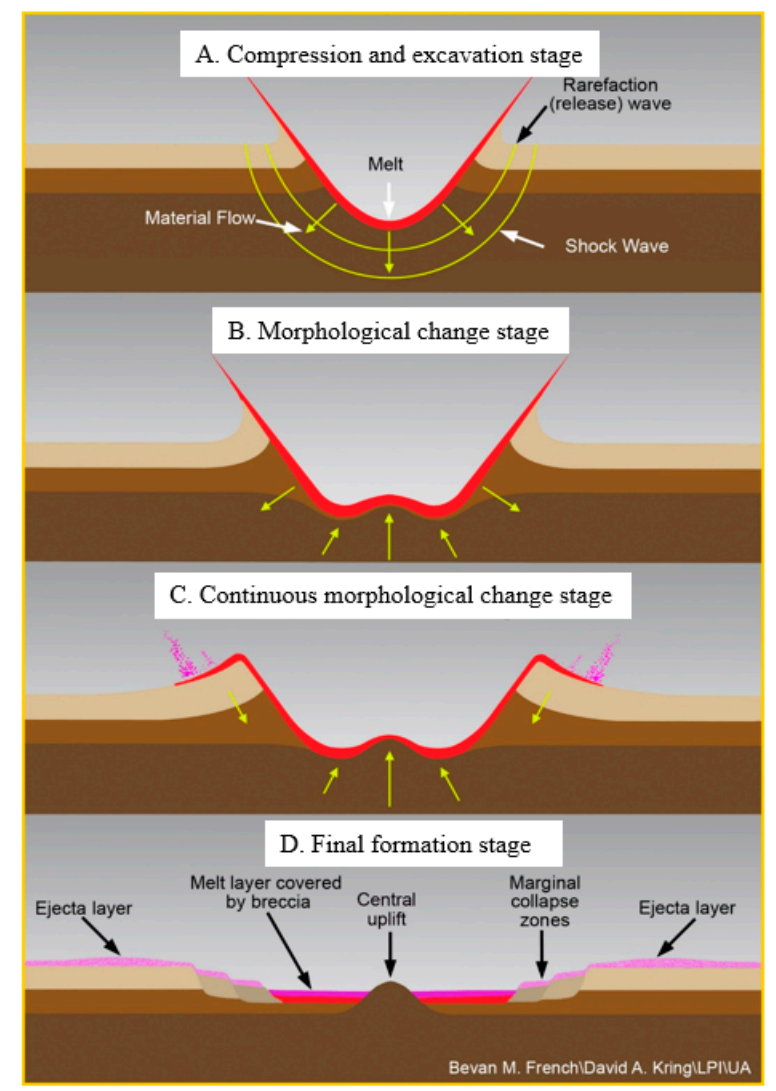

Figure 1. Formation process of an impact crater (modified from [48]).

Based on the formation process of impact craters, fundamental geometric indices for individual impact craters are designed, including crater diameter, depth, volume, circularity, posture ratio, sphericity, and depth-diameter ratio. These indices can be deduced directly from the shape and boundary conditions of impact craters, and to further determine other indices, namely surface diameter, transient diameter, maximum depth, and impact crater depth. It should be noted that, for easy calculation and expression, the 'pithead' is determined as the best-fit ellipse of the crater rim, so that some indices can be calculated accordingly. All indices used to express basic geometry are shown in Table 1 and Figure 2. 
Table 1. Indices for description of the basic geometry.

\begin{tabular}{|c|c|c|c|c|c|}
\hline & Index & Definition & Calculation Method & Significance of Index & Legend Description \\
\hline \multirow{3}{*}{ Diameter } & CDiameter & Diameter of impact crater & $\begin{array}{l}\text { It can be calculated using the diameter of a circle possessing the } \\
\text { same area as that of the pithead [49] }\end{array}$ & $\begin{array}{l}\text { Reflects the generic diameter of } \\
\text { the crater }\end{array}$ & \\
\hline & Surface diameter & $\begin{array}{l}\text { Diameter of the plane with an } \\
\text { average elevation where the } \\
\text { impact occurs }\end{array}$ & $\begin{array}{l}\qquad D_{a}=\sqrt{4 \text { Area } / \pi} \\
\text { Area is the area of impact crater }[50,51]\end{array}$ & $\begin{array}{l}\text { Reflects the diameter of the crater } \\
\text { in the final state }\end{array}$ & \multirow[b]{2}{*}{ Figure 2a } \\
\hline & Transient diameter & $\begin{array}{l}\text { Diameter of crater formed by particle } \\
\text { flow in the shock wave at the } \\
\text { beginning impact }\end{array}$ & $\begin{array}{l}\qquad D_{s}=R+C_{c}-C_{I} \\
R \text { is the diameter of the impact crater; } C_{I} \text { is the outer ring of the } \\
\text { curvature on the pithead; } C_{c} \text { is the inner ring of the curvature } \\
\text { on the pithead }[50,51]\end{array}$ & $\begin{array}{l}\text { Reflects the diameter of the crater } \\
\text { at the moment of impact }\end{array}$ & \\
\hline \multirow{2}{*}{ Depth } & Maximum crater depth & $\begin{array}{l}\text { Distance from the highest point of } \\
\text { the crater to the bottom of material } \\
\text { on the bottom of the crater }\end{array}$ & $\begin{array}{c}\mathrm{H}_{\mathrm{a}} \approx 1.83 \mathrm{D}_{\mathrm{a}}^{0.10} \\
\mathrm{D}_{\mathrm{a}} \text { is the surface diameter }[50,51]\end{array}$ & $\begin{array}{l}\text { Reflects the depth of the crater } \\
\text { immediately after an impact }\end{array}$ & \multirow{2}{*}{ Figure $2 b$} \\
\hline & Impact crater depth & $\begin{array}{l}\text { Distance from the highest point of } \\
\text { the crater to the top of material on } \\
\text { the bottom of the crater }\end{array}$ & $\begin{array}{c}\mathrm{H}_{\mathrm{TC}} \approx 0.6 \mathrm{H}_{\mathrm{a}} \\
\mathrm{H}_{\mathrm{a}} \text { is the maximum of depth of impact crater }[50,51]\end{array}$ & $\begin{array}{l}\text { Reflects the final depth of } \\
\text { the crater }\end{array}$ & \\
\hline & Volume & $\begin{array}{l}\text { Volume of impact crater bounded by } \\
\text { the crater bottom and walls }\end{array}$ & $\begin{array}{c}V=\left(S+\sqrt{S * S^{\prime}}+S^{\prime}\right) H a \div 3 \\
S \text { is the area of the pithead } \\
S^{\prime} \text { is the area of the bottom } \\
\mathrm{H}_{\mathrm{a}} \text { is the maximum of depth of the impact crater }[50,51]\end{array}$ & $\begin{array}{l}\text { Reflects the size of the volume of } \\
\text { the crater }\end{array}$ & \\
\hline & Circularity & $\begin{array}{l}\text { The degree of the shape of an impact } \\
\text { crater that approximate to a circle }\end{array}$ & $\begin{array}{l}\mathrm{C}=\mathrm{P} /\left(2^{*} \sqrt{ }\left(\pi^{*} \mathrm{~A}\right)\right) \\
\mathrm{P} \text { is the perimeter of the crater, } \mathrm{A} \text { is the area of the crater }\end{array}$ & $\begin{array}{l}\text { Reflects the complexity of the } \\
\text { boundary of the crater }\end{array}$ & \\
\hline \multicolumn{2}{|r|}{ Posture ratio } & $\begin{array}{l}\text { The ratio between the width }(\mathrm{W}) \text { and } \\
\text { the length }(\mathrm{L}) \text { of the minimum } \\
\text { bounding rectangle }\end{array}$ & $\begin{array}{l}\mathrm{C}=\mathrm{W} / \mathrm{L} \\
\mathrm{L} \text { is the length of the minimum bounding rectangle; } \mathrm{W} \text { is the } \\
\text { width of the minimum bounding rectangle }\end{array}$ & Reflects the rigidity of the crater & \multirow{2}{*}{ Figure $2 c$} \\
\hline & Sphericity & $\begin{array}{l}\text { The ratio between inscribed circle } \\
\text { radius } R_{I} \text { and excircle radius } R_{C}\end{array}$ & $\begin{array}{l}\qquad S=R_{I} / R_{C} \\
R_{I} \text { is the radius of inscribed circle; } R_{C} \text { is the radius of excircle. }\end{array}$ & $\begin{array}{l}\text { Reflects the closeness degree of } \\
\text { the impact crater to a circle }\end{array}$ & \\
\hline & pth-diameter ratio & $\begin{array}{l}\text { The ratio between the depth (D) to } \\
\text { the diameter length (DL) of the crater. }\end{array}$ & $\begin{array}{c}\mathrm{D} / \mathrm{DL} \\
\mathrm{D} \text { is the depth of the crater; } \mathrm{DL} \text { is the diameter length }\end{array}$ & $\begin{array}{l}\text { Reflects the degree of } \\
\text { development of the crater }\end{array}$ & \\
\hline
\end{tabular}



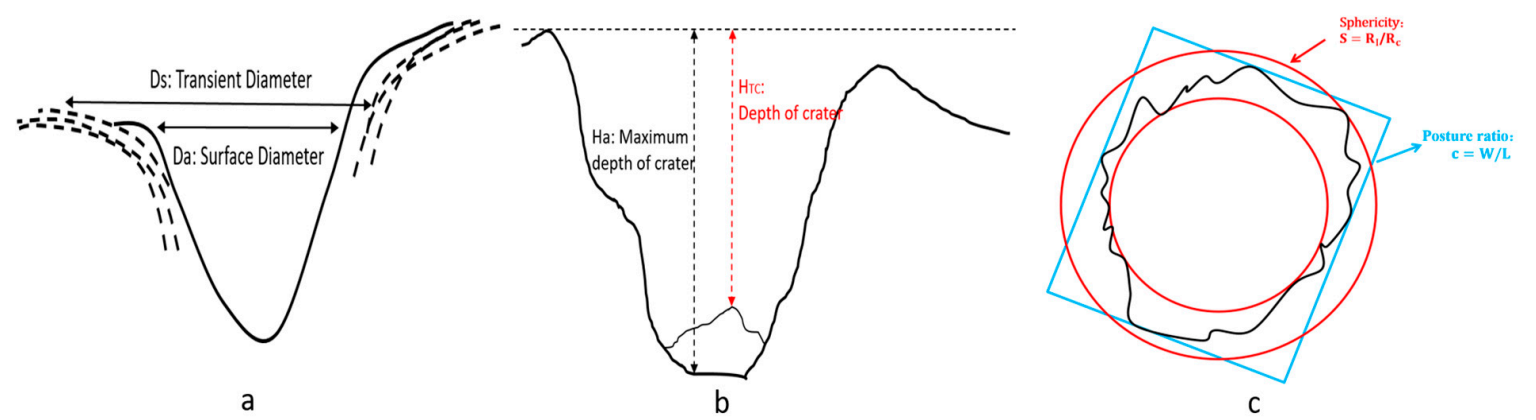

Figure 2. Schematic description of some of the indices in Table 1. (a) Diameter; (b) Depth; (c) Posture ratio and Sphericity.

\subsubsection{Crater Rim and Corresponding Indices}

As impact energies are normally very high, impact events will lead to vigorous excavation processes. There will be uplift in the impacted area and inner materials will be deposited around the uplifted area to form a raised boundary, i.e., the crater rim. When the crater has just formed, the crater rim is relatively smooth and clean but, due to a long period of erosion, secondary impacts, and exogenetic processes, the crater rim becomes discontinuous, jagged, and fragmented (Figure 3 ). Therefore, the rims of large craters are always embedded with other impact craters of either simple or complex shape.

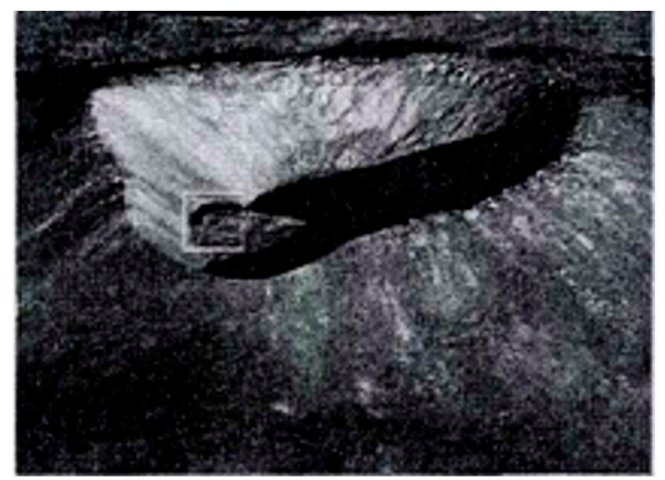

A smooth crater rim

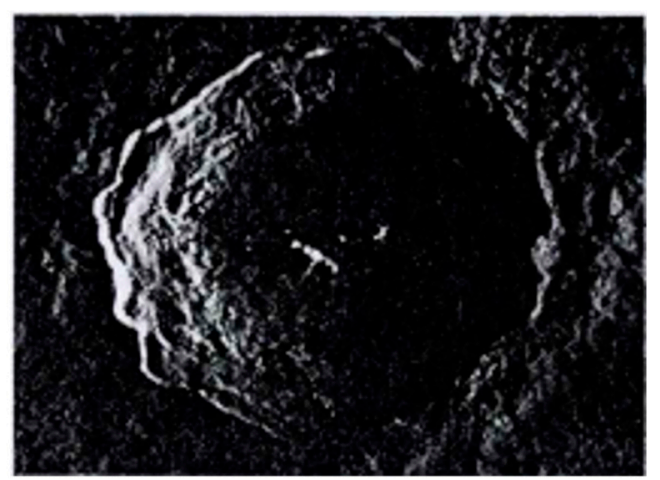

A jagged and fragmented crater rim

Figure 3. Crater rim shapes (from NASA, [52]).

The degree of completeness of a crater rim typically depends on its formation age. The slopes of crater rims differ on the inside and outside. The inner slopes are typically $35^{\circ}$, and range from $25^{\circ}$ to $50^{\circ}$. The outside slopes are relatively gentle, typically $5^{\circ}$, ranging from $3^{\circ}$ to $5^{\circ}$ [2].

To describe the characteristics of crater rims, the following indices were designed (Table 2, Figures 4 and 5): pithead diameter, pithead area, width of the crater rim, accumulation form of the crater rim, slope of the crater rim, etc. Because the shape of the crater rim is irregular, the long and short axes of the smallest bounding rectangle are taken as the long and short axes of the pithead. Due to the randomness of slope, they are classified statistically by intervals. 
Table 2. Indices for description of the crater rim.

\begin{tabular}{|c|c|c|c|c|c|}
\hline Ind & & Definition & Calculation Method & Significance of Index & Legend Description \\
\hline \multirow{2}{*}{ Pithead diameter } & Long diameter & $\begin{array}{l}\text { The longest diameter } \\
\text { through the pithead }\end{array}$ & MBR method & \multirow{2}{*}{$\begin{array}{l}\text { Reflects the flattening of } \\
\text { the pithead. }\end{array}$} & \multirow{2}{*}{ Figure 4} \\
\hline & Short diameter & $\begin{array}{l}\text { The shortest diameter } \\
\text { through the pithead }\end{array}$ & MBR method & & \\
\hline \multicolumn{2}{|c|}{ Width of the rim } & $\begin{array}{l}\text { The difference between the } \\
\text { outer ring radius }\left(C_{I}\right) \text { and } \\
\text { the inner ring radius }\left(C_{C}\right)\end{array}$ & $\begin{array}{c}C_{W}=C_{I}-C_{C} \\
C_{I} \text { is the slope variability line outside the } \\
\text { pithead ring } \\
C_{C} \text { for the slope variability line inside } \\
\text { the pithead ring }\end{array}$ & $\begin{array}{l}\text { Reflects the degree of the } \\
\text { erosion of the rim. }\end{array}$ & \multirow{4}{*}{ Figure 5} \\
\hline \multicolumn{2}{|c|}{ Pithead area } & $\begin{array}{l}\text { The area } \\
\text { surrounded by the rim }\end{array}$ & $\begin{array}{l}\text { Using Arcgis Calculate Geometry } \\
\text { (https://www.arcgis.com/) }\end{array}$ & $\begin{array}{l}\text { Reflects the size of } \\
\text { the pithead }\end{array}$ & \\
\hline \multicolumn{2}{|c|}{ Accumulation form of the rim } & $\begin{array}{l}\text { Deposit formation on } \\
\text { unilateral rim }\end{array}$ & - & $\begin{array}{l}\text { Reflects the development of } \\
\text { the rim }\end{array}$ & \\
\hline \multicolumn{2}{|c|}{ Slope of the crater rim } & $\begin{array}{c}\text { The angle between the rim } \\
\text { and the horizontal direction } \\
\text { of the pithead }\end{array}$ & Statistical grading $\left(0 \sim 5^{\circ}, 5^{\circ} \sim 15^{\circ},>25^{\circ}\right)$ & $\begin{array}{l}\text { Reflects the initial direction } \\
\text { of the impact crater at the } \\
\text { moment of impact }\end{array}$ & \\
\hline
\end{tabular}




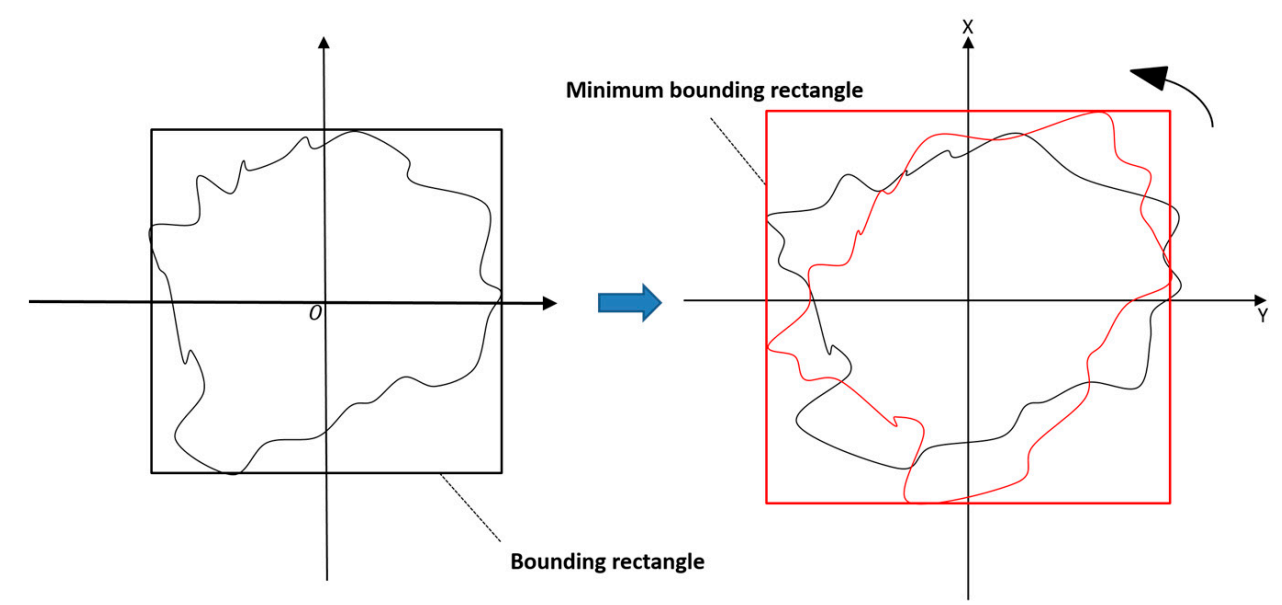

Figure 4. Application of the minimum bounding rectangle calculation.

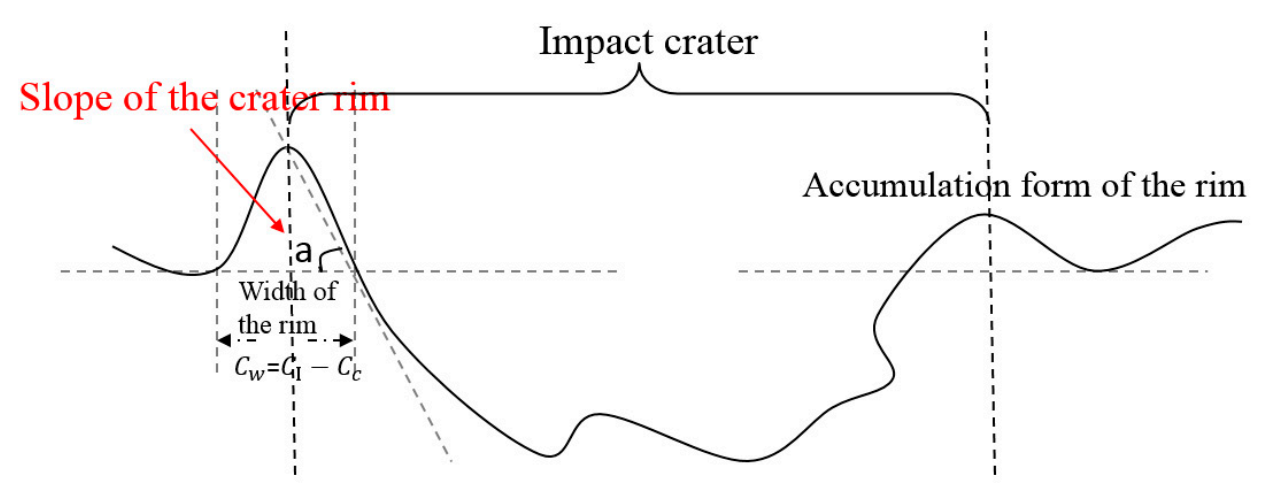

Figure 5. Schematic description of some of the indices in Table 2.

In Table 2, the minimum bounding rectangle (MBR) calculation contains the following steps. The object and its boundary are rotated by $15^{\circ}$ increments until they reached a maximum angle, i.e., $90^{\circ}$, with respect to their original position. For each rotation, the area of its bounding rectangle is recorded, and the one with the smallest area is regarded as the smallest bounding rectangle, whose axes can be treated as the long and short axes of the object.

\subsubsection{Crater Wall and Corresponding Indices}

The crater wall is formed during early-stage debris deposition, followed by embedding processes due to secondary or later impacts, and is overlaid with loose material from unstable terraces. In general, small impact craters often display smooth walls with steady slopes, and the walls of impact craters formed during remote periods and with diameters of 5-20 km often experience gradual collapse [2]. The walls of the crater often comprise trapezoidal or irregular terraces (Figure 6).

Descriptive indices for the crater wall are as follows: inner slope of the crater wall, outer slope of the crater wall, average slope of the crater wall, and roughness (Table 3 and Figure 7). The outer crater wall is typically connected with the plain and experiences less erosion, so is relatively gentle. Due to collapse of deposited materials, the inner wall suffers more erosion and is relatively steep. The average slope is calculated from the average value of crater wall slopes. With the help of digital elevation model (DEM) data and the slope function in ArcGIS, different slope indices can be obtained to describe the crater walls. 


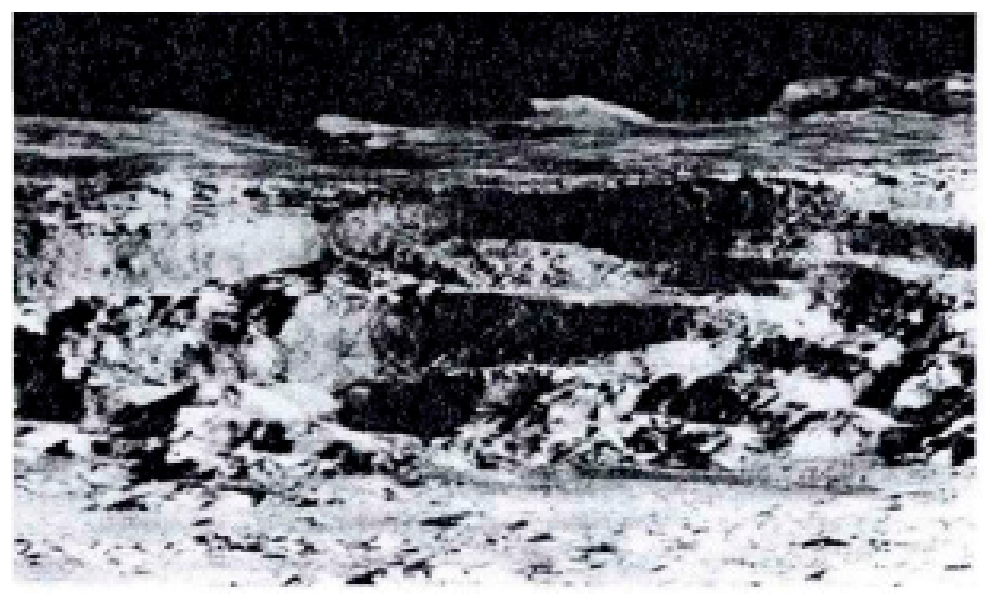

Figure 6. The inner crater wall of Copernicus (from NASA, [52]).

Table 3. Indices for description of the crater wall.

\begin{tabular}{|c|c|c|c|c|}
\hline Index & Definition & $\begin{array}{l}\text { Calculation } \\
\text { Method }\end{array}$ & Significance of Index & $\begin{array}{c}\text { Legend } \\
\text { Description }\end{array}$ \\
\hline Average slope & $\begin{array}{l}\text { The value of the } \\
\text { mean slope of the } \\
\text { crater wall }\end{array}$ & Using Arcgis Slope & $\begin{array}{l}\text { Reflects the steepness } \\
\text { of the crater wall }\end{array}$ & \multirow{4}{*}{ Figure 7} \\
\hline Inner slope & $\begin{array}{l}\text { The value of the } \\
\text { slope for the steep } \\
\text { side }\end{array}$ & Using Arcgis Slope & $\begin{array}{l}\text { Reflects the degree of } \\
\text { steepness of the crater } \\
\text { wall inside the crater }\end{array}$ & \\
\hline Outer slope & $\begin{array}{l}\text { The value of the } \\
\text { slope for the side } \\
\text { connected to the } \\
\text { plain }\end{array}$ & Using Arcgis Slope & $\begin{array}{l}\text { Reflects the steepness } \\
\text { of the crater wall } \\
\text { connected to the plain }\end{array}$ & \\
\hline Roughness & $\begin{array}{l}\text { Number of steps } \\
\text { on the crater wall } \\
\text { from bottom to top }\end{array}$ & Using Arcgis Slope & $\begin{array}{l}\text { Reflects the degree of } \\
\text { degradation of the } \\
\text { crater wall }\end{array}$ & \\
\hline
\end{tabular}

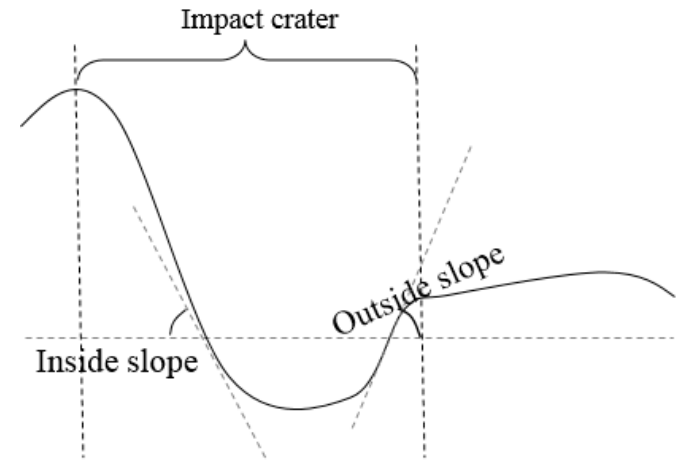

Figure 7. Schematic description for some of the indices in Table 3.

\subsubsection{Crater Floor and Corresponding Indices}

The crater floor is the base of the depression formed by impact. Smooth crater floors are typically found in impact craters with relatively small diameters. On some crater floors, there are often small, scattered domes or loose material from the crater walls. The central part of the crater floor is significantly uplifted in many large impact craters (Figure 8), and impact craters with a diameter of 5-40 km often have eddy-shaped floors [2]. For large-scale multi-ring basins, nodule-shaped deposits are often generated during transformation and development of the central peak. 


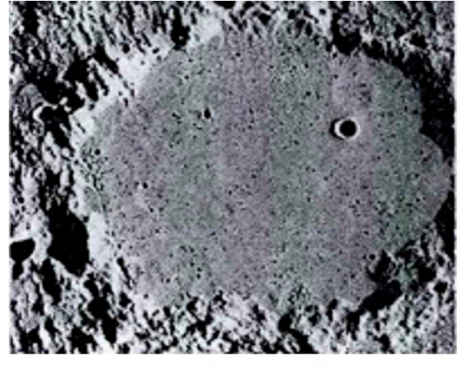

A smooth crater floor

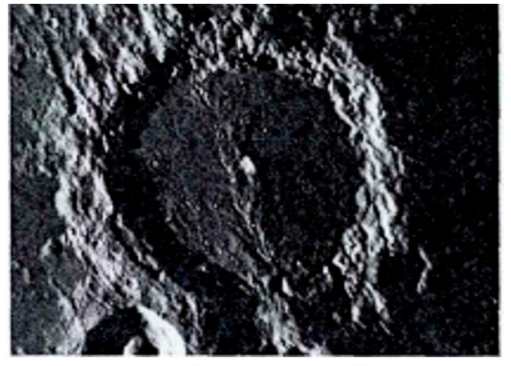

A protuberant crater floor

Figure 8. Crater floor shapes (from NASA, [52]).

The following descriptive indices are designed to describe crater floor characteristics: floor diameter, floor area, floor slope, floor roughness, floor circularity, posture ratio of the floor, floor sphericity, and overlap of crater floor and crater boundary (see Table 4 and Figure 9). Among these indices, the roughness of the floor can be used to reflect the erosion degree of the surface, its subsidence and uplift, and can be obtained using the slope function in ArcGIS. The overlap of the crater floor and crater boundary can be used to test whether their principle directions are identical. From their dislocation relationship, the impact direction of the first impact and the sequence of superimposed impacts can be deduced.

Table 4. Indices for description of the crater floor.

\begin{tabular}{|c|c|c|c|c|c|}
\hline \multicolumn{2}{|c|}{ Index } & Definition & Calculation Method & $\begin{array}{l}\text { Significance of } \\
\text { Index }\end{array}$ & $\begin{array}{c}\text { Legend } \\
\text { Description }\end{array}$ \\
\hline \multirow{2}{*}{ Floor diameter } & Long diameter & $\begin{array}{l}\text { The longest diameter } \\
\text { through the floor }\end{array}$ & Using MER method & \multirow{2}{*}{$\begin{array}{l}\text { Reflects the } \\
\text { flattening of } \\
\text { the floor }\end{array}$} & \multirow{2}{*}{ Figure $9 a$} \\
\hline & Short diameter & $\begin{array}{l}\text { The shortest diameter } \\
\text { through the floor }\end{array}$ & Using MER method & & \\
\hline \multicolumn{2}{|c|}{ Floor area } & $\begin{array}{l}\text { The area that is } \\
\text { enclosed by the slope } \\
\text { variability line in } \\
\text { the floor }\end{array}$ & $\begin{array}{c}\text { Using Arcgis Calculate } \\
\text { Geometry }\end{array}$ & $\begin{array}{l}\text { Reflects the size } \\
\text { of the floor }\end{array}$ & \\
\hline \multicolumn{2}{|c|}{ Floor slope } & Slope of the floor & Using Arcgis Slope & $\begin{array}{l}\text { Reflects the } \\
\text { steepness of } \\
\text { the floor }\end{array}$ & Figure $9 b$ \\
\hline \multicolumn{2}{|c|}{ Floor roughness } & $\begin{array}{l}\text { Ladder number of } \\
\text { the floor }\end{array}$ & Using Arcgis Slope & $\begin{array}{l}\text { Reflects the } \\
\text { degree of erosion } \\
\text { of the floor }\end{array}$ & \\
\hline \multicolumn{2}{|c|}{ Floor circularity } & $\begin{array}{l}\text { The degree of the } \\
\text { shape of the floor of an } \\
\text { impact crater that } \\
\text { approximate to a circle }\end{array}$ & $\begin{array}{l}\mathrm{C}=\mathrm{P} /\left(2^{*} \sqrt{ }\left(\pi^{*} \mathrm{~A}\right)\right) \\
\mathrm{P} \text { is the perimeter of } \\
\text { the floor of the crater, } \\
\mathrm{A} \text { is the area of the } \\
\text { floor of the crater }\end{array}$ & $\begin{array}{l}\text { Reflects the } \\
\text { complexity of the } \\
\text { boundary of } \\
\text { the floor }\end{array}$ & \\
\hline \multicolumn{2}{|c|}{ Posture ratio of the floor } & $\begin{array}{l}\text { The ratio between the } \\
\text { width }(\mathrm{W}) \text { and the } \\
\text { length }(\mathrm{L}) \text { of the } \\
\text { minimum } \\
\text { bounding rectangle }\end{array}$ & $\begin{array}{l}\mathrm{C}=\mathrm{W} / \mathrm{L} \\
\mathrm{L} \text { is the length of the } \\
\text { minimum bounding } \\
\text { rectangle; } \mathrm{W} \text { is the } \\
\text { width of the minimum } \\
\text { bounding rectangle }\end{array}$ & $\begin{array}{l}\text { Reflects the } \\
\text { rigidity of } \\
\text { the floor }\end{array}$ & \\
\hline \multicolumn{2}{|c|}{ Floor sphericity } & $\begin{array}{c}\text { The ratio between } \\
\text { inscribed circle radius } \\
\mathrm{R}_{\mathrm{I}} \text { and excircle } \\
\text { radius } \mathrm{R}_{\mathrm{C}}\end{array}$ & $\begin{array}{l}\quad S=R_{I} / R_{C} \\
R_{I} \text { is the radius of } \\
\text { inscribed circle; } R_{C} \text { is } \\
\text { the radius of excircle }\end{array}$ & $\begin{array}{l}\text { Reflect the } \\
\text { closeness of the } \\
\text { floor to a circle }\end{array}$ & \\
\hline \multicolumn{2}{|c|}{$\begin{array}{l}\text { Overlap of crater floor and crater } \\
\text { boundary }\end{array}$} & $\begin{array}{l}\text { Whether the main } \\
\text { directions of crater } \\
\text { floor and crater } \\
\text { boundary are the same }\end{array}$ & $\begin{array}{l}\text { Dislocation } \\
\text { relationship } \rightarrow \text { impact } \\
\text { direction }\end{array}$ & $\begin{array}{l}\text { Reflect the } \\
\text { direction of } \\
\text { the impact }\end{array}$ & \\
\hline
\end{tabular}




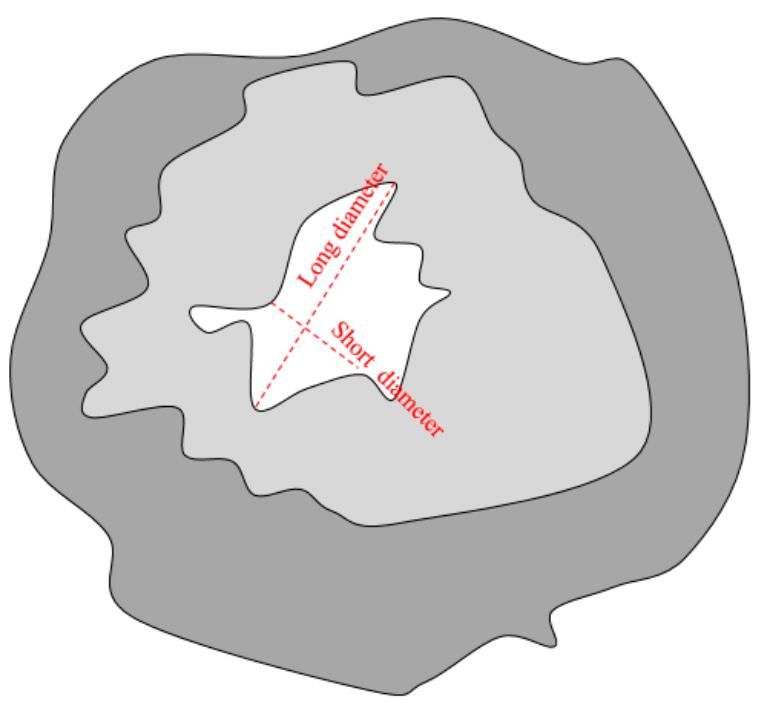

a

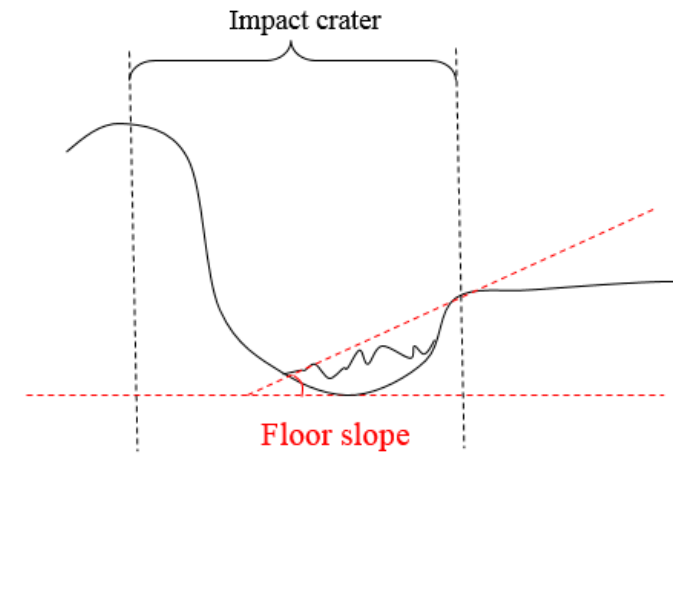

b

Figure 9. (a,b) Schematic description for some of the indices in Table 4.

\subsubsection{Central Peak and Corresponding Indices}

Central peaks of craters (as shown in Figure 10) are developed during later stages of crater formation and are predominantly found at the geometric centre of crater floors in impact craters with a diameter of $35 \mathrm{~km}$ or above. Some peaks, however, may be located beside the centre. Their heights are typically close to or slightly lower than their ring-shaped crater walls. The appearance of central peaks can be regarded as a geological mass balance related to a previous collapse, so collapses are always noted on the periphery of impact craters with central peaks [53].

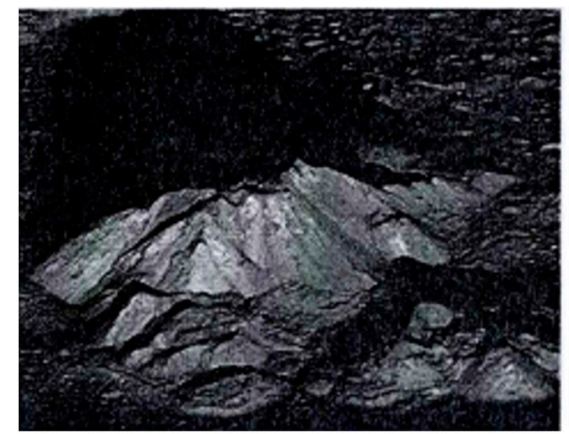

Central peak of the crater

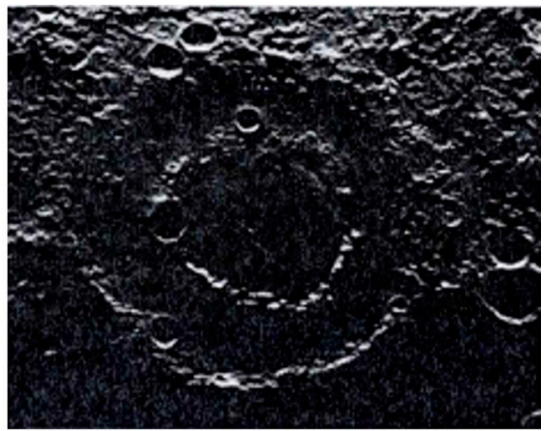

Central ring of the crater

Figure 10. Central peak shapes (from NASA, [52]).

According to Ouyang [32], central peaks are typically formed in impact craters of 15 to $150 \mathrm{~km}$ diameter. When the crater diameter approaches $80 \mathrm{~km}$, the height and volume of the central peak increase, and multiple central peaks may develop simultaneously at a certain point. When the diameter of the impact crater exceeds $80 \mathrm{~km}$, the central peak height and volume decrease at different rates, possibly resulting in a central ring. For craters with diameters of $150-250 \mathrm{~km}$, transformation often occurs, and they normally form multi-ring basins.

Based on the above characteristics, the descriptive indices for central peaks are shown in Table 5 and Figure 11, and include central peak height, diameter of the ring of the central peak, base diameter of the central peak, base area of the central peak, and number of peak rings in the central peak. Here, the pithead diameter $\left(D_{\mathrm{rc}}\right)$ can be employed to help calculate some indices, such as central peak height and base area of the central peak, according to previous statistical data [53]. 
Table 5. Indices for description of the central peaks.

\begin{tabular}{|c|c|c|c|c|}
\hline Index & Definition & Calculation Method & Significance of Index & $\begin{array}{c}\text { Legend } \\
\text { Description }\end{array}$ \\
\hline Central peak height & $\begin{array}{l}\text { Height of the } \\
\text { central peak }\end{array}$ & $\begin{array}{c}\mathrm{H} \approx 0.006 \mathrm{D}_{\mathrm{rc}}{ }^{1.28} \\
\mathrm{D}_{\mathrm{rc}} \text { is the pithead diameter } \\
\text { of the crater }[53]\end{array}$ & $\begin{array}{l}\text { Reflects height of the } \\
\text { central peak }\end{array}$ & \multirow{5}{*}{ Figure 11} \\
\hline $\begin{array}{l}\text { Diameter of the } \\
\text { adjacent peak ring }\end{array}$ & $\begin{array}{l}\text { The distance between } \\
\text { the adjacent peak rings }\end{array}$ & $\begin{array}{c}\mathrm{D}_{\mathrm{ij}}=\mathrm{D}_{\mathrm{i}} / 2+\mathrm{D}_{\mathrm{j}} / 2 \\
\mathrm{D}_{\mathrm{i}}, \mathrm{D}_{\mathrm{j}} \text { are the base } \\
\text { diameters of the two } \\
\text { adjacent central peaks }\end{array}$ & $\begin{array}{l}\text { Reflects the size of the } \\
\text { peak ring of the } \\
\text { central peak }\end{array}$ & \\
\hline Base diameter & $\begin{array}{l}\text { The diameter of the } \\
\text { contour of the central } \\
\text { peak base }\end{array}$ & $\begin{array}{c}\mathrm{D}_{\mathrm{cp}}=0.259 \mathrm{D}_{\mathrm{rc}}-2.5 \\
\mathrm{D}_{\mathrm{rc}} \text { is the pithead diameter } \\
\text { of the crater, and the unit } \\
\text { of } 2.5 \text { is } \mathrm{Km}[53]\end{array}$ & $\begin{array}{l}\text { Reflects the size of the } \\
\text { development profile of } \\
\text { the central peak base }\end{array}$ & \\
\hline Base area & $\begin{array}{l}\text { The area enclosed by } \\
\text { the contour of the } \\
\text { central peak base }\end{array}$ & $\begin{array}{l}\text { Using Arcgis } \\
\text { Calculate Geometry }\end{array}$ & $\begin{array}{l}\text { Reflects the size of the } \\
\text { central peak base }\end{array}$ & \\
\hline $\begin{array}{l}\text { Number of peak } \\
\text { rings in the } \\
\text { central peak }\end{array}$ & $\begin{array}{l}\text { The number of peaks } \\
\text { in the central peak }\end{array}$ & - & $\begin{array}{l}\text { Reflects the degree of } \\
\text { the development of the } \\
\text { central peak }\end{array}$ & \\
\hline
\end{tabular}

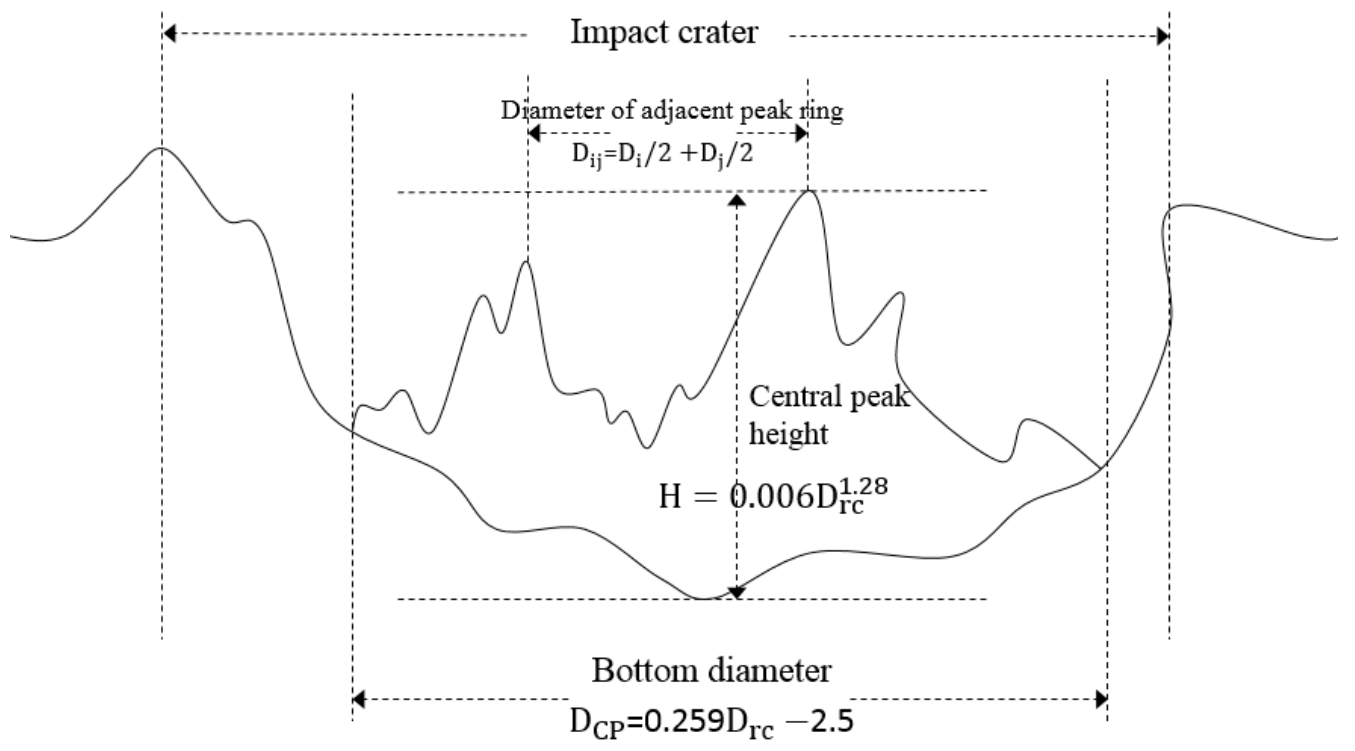

Figure 11. Schematic description of some of the indices in Table 5.

\subsubsection{Ejecta and Corresponding Indices}

The energy of impacting high-speed meteoroids causes rocks in the crater to melt, and the high impact speed results in the molten rock accumulating inwards and spattering outwards. The molten rocks are deposited inside or outside the crater in different forms after cooling and are referred to as ejecta.

Therefore, the descriptive indices of ejecta mainly include width, thickness, and volume $[54,55]$. Indices for flow characteristics and coverage of ejecta can also be designed to describe other morphological features of impact crater ejecta (Table 6 and Figure 12). 
Table 6. Indices for description of ejecta.

\begin{tabular}{|c|c|c|c|c|}
\hline Index & Definition & Calculation Method & $\begin{array}{l}\text { Significance of } \\
\text { Index }\end{array}$ & $\begin{array}{c}\text { Legend } \\
\text { Description }\end{array}$ \\
\hline Ejecta width & $\begin{array}{l}\text { The difference between the } \\
\text { radius of the inner ring } \\
\text { and the radius of the outer } \\
\text { ring of continuous ejecta }\end{array}$ & $\begin{array}{c}\mathrm{R}_{\mathrm{C}}=0.86 \mathrm{R}_{\mathrm{TC}}^{1.07} \\
\mathrm{R}_{\mathrm{TC}} \text { is instantaneous impact width }[54,55]\end{array}$ & $\begin{array}{l}\text { Reflects the } \\
\text { sputtering range } \\
\text { of ejecta }\end{array}$ & \multirow{3}{*}{ Figure $12 \mathrm{a}$} \\
\hline Ejecta thickness & $\begin{array}{l}\text { Thickness of ejecta in } \\
\text { different crater locations }\end{array}$ & $\begin{array}{l}\quad \delta=0.14 \mathrm{R}_{\mathrm{C}}{ }^{0.74}\left(\frac{R}{R_{c}}\right)^{-3.0 \pm 0.5} \\
\mathrm{R} \text { is the distance to the impact point; } \mathrm{R}_{\mathrm{C}} \\
\text { sputter width }[54,55]\end{array}$ & $\begin{array}{c}\text { Reflects the } \\
\text { deposited } \\
\text { thickness of ejecta }\end{array}$ & \\
\hline Ejecta volume & The volume of ejecta & $\begin{array}{l}\mathrm{V}_{\text {melt }}=\left(3.9890 \times 10^{-8}\right) \pi \mathrm{D}_{\mathrm{TC}}{ }^{3.83} V_{i}^{0.33} \\
\mathrm{D}_{\mathrm{TC}} \text { is the instantaneous diameter of } \\
\text { crater; } V_{i} \text { is the impact speed }[54,55]\end{array}$ & $\begin{array}{l}\text { Reflects the size of } \\
\text { the settlement } \\
\text { of ejecta }\end{array}$ & \\
\hline $\begin{array}{l}\text { Ejecta flow } \\
\text { direction }\end{array}$ & $\begin{array}{l}\text { The distribution of ejecta } \\
\text { around or on one side of } \\
\text { a crater }\end{array}$ & Six-direction grading method & $\begin{array}{c}\text { Reflects the } \\
\text { sputtering } \\
\text { direction of ejecta }\end{array}$ & \multirow{3}{*}{ Figure $12 b$} \\
\hline $\begin{array}{l}\text { Ejecta } \\
\text { overlying } \\
\text { relation }\end{array}$ & $\begin{array}{l}\text { Overlying relationships } \\
\text { of ejecta of } \\
\text { different lithologies }\end{array}$ & Not covered, partially covered, covered & $\begin{array}{c}\text { Reflects the } \\
\text { stratigraphy of } \\
\text { spattered ejecta }\end{array}$ & \\
\hline Ejecta area & $\begin{array}{l}\text { The area with the } \\
\text { maximum radius of the } \\
\text { ejecta around the crater }\end{array}$ & Using Arcgis & $\begin{array}{l}\text { Reflects the } \\
\text { sputtering range } \\
\text { of ejecta }\end{array}$ & \\
\hline
\end{tabular}

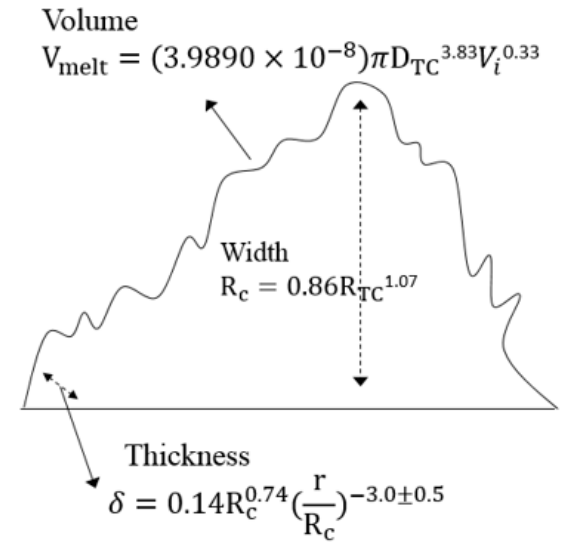

a

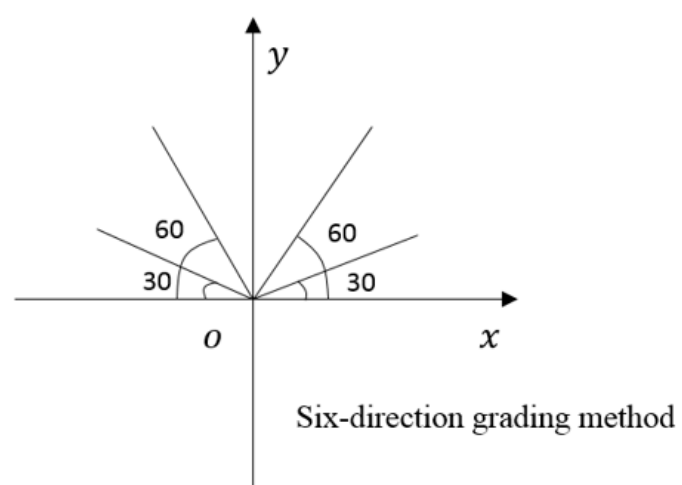

b

Figure 12. Schematic description for some of the indices in Table 6. (a) Ejecta volume; (b) Ejecta flow direction.

\subsection{Descriptive Indices for Crater Groups}

Lunar craters are distributed randomly over the Moon's surface. There are more than 33,000 impact craters with a diameter greater than $1 \mathrm{~km}$. In general, craters are more densely distributed over more ancient Moon surfaces, and crater density is small in the lunar maria [54].

To describe the group features of lunar impact craters, descriptive indices can be classified according to their statistical and spatial distribution characteristics (Table 7). Statistical characteristic indices include waviness, difference of slope, difference of height, roughness, slope, circularity, diameter, depth, and depth-diameter ratio. Each of the latter six indices can be separated into eight sub-indices, including average value, maximum value, minimum value, standard deviation, median, mode, kurtosis, and skewness, to represent static figures of the above characteristics. The spatial distribution indices are illustrated by degree of fragmentation, degree of aggregation, density, and Moran's Index. 


$$
I=\frac{n}{\sum i \sum j w_{i, j}} \frac{\sum i \sum j w_{i, j}\left(x_{i}-\bar{x}\right)\left(x_{j}-\bar{x}\right)}{\sum i\left(x_{i}-\bar{x}\right)^{2}}
$$

Table 7. Indices for description of crater groups (indices in red can be separated into eight sub-indices, see Section 2.2).

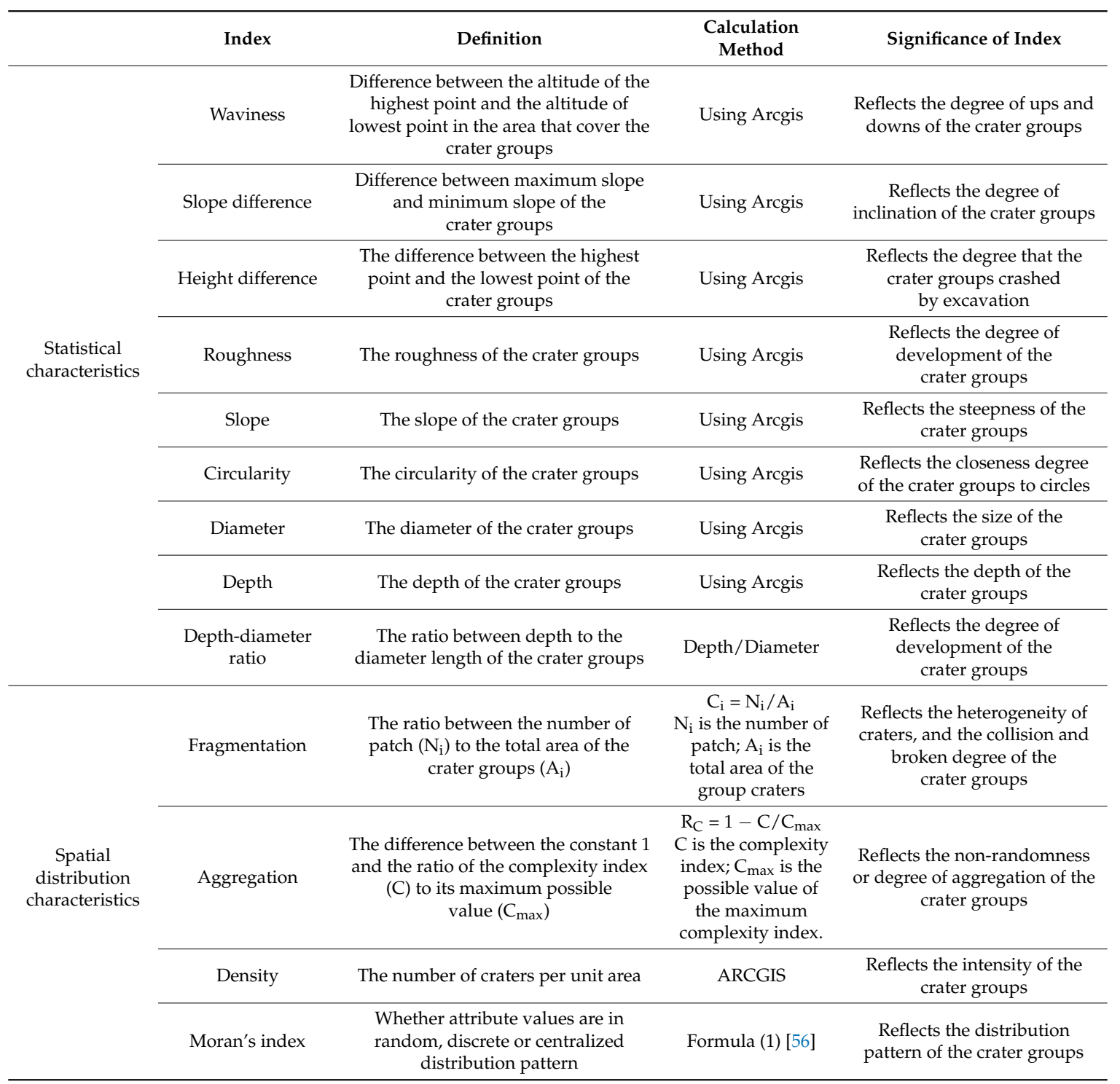

\section{Structured Representation of Lunar Impact Crater Descriptive Indices}

For different types or components of lunar impact craters, the descriptive indices may differ. Organising these indices in a structured way is fundamental for the convenient use of these descriptive indices, e.g., computer processing and calculation, querying and searching, and knowledge sharing of lunar information.

The structured expression of descriptive indices in this study involves a data organisation method based on the analysis of geometric elements and the spatial distribution of crater groups. This structured organisation method has two parts: metadata organisation and index content organisation. 


\subsection{Metadata Organisation of Descriptive Indices}

This part describes the metadata of a descriptive index document or file. It includes (1) keywords, which are used to create an impact crater directory and enable rapid searching and classification of crater indices; (2) version numbers, which denote the version of the index data file; (3) document introduction, which briefly describes the index data file; (4) information related to file creation, modification, and distribution, which contains the corresponding (creation/modification/distribution) personnel, time, and venue; (5) information related to file storage and access; and (6) contact information (e.g., person or department). The UML (unified modelling language) diagram for impact crater metadata is shown in Figure 13.

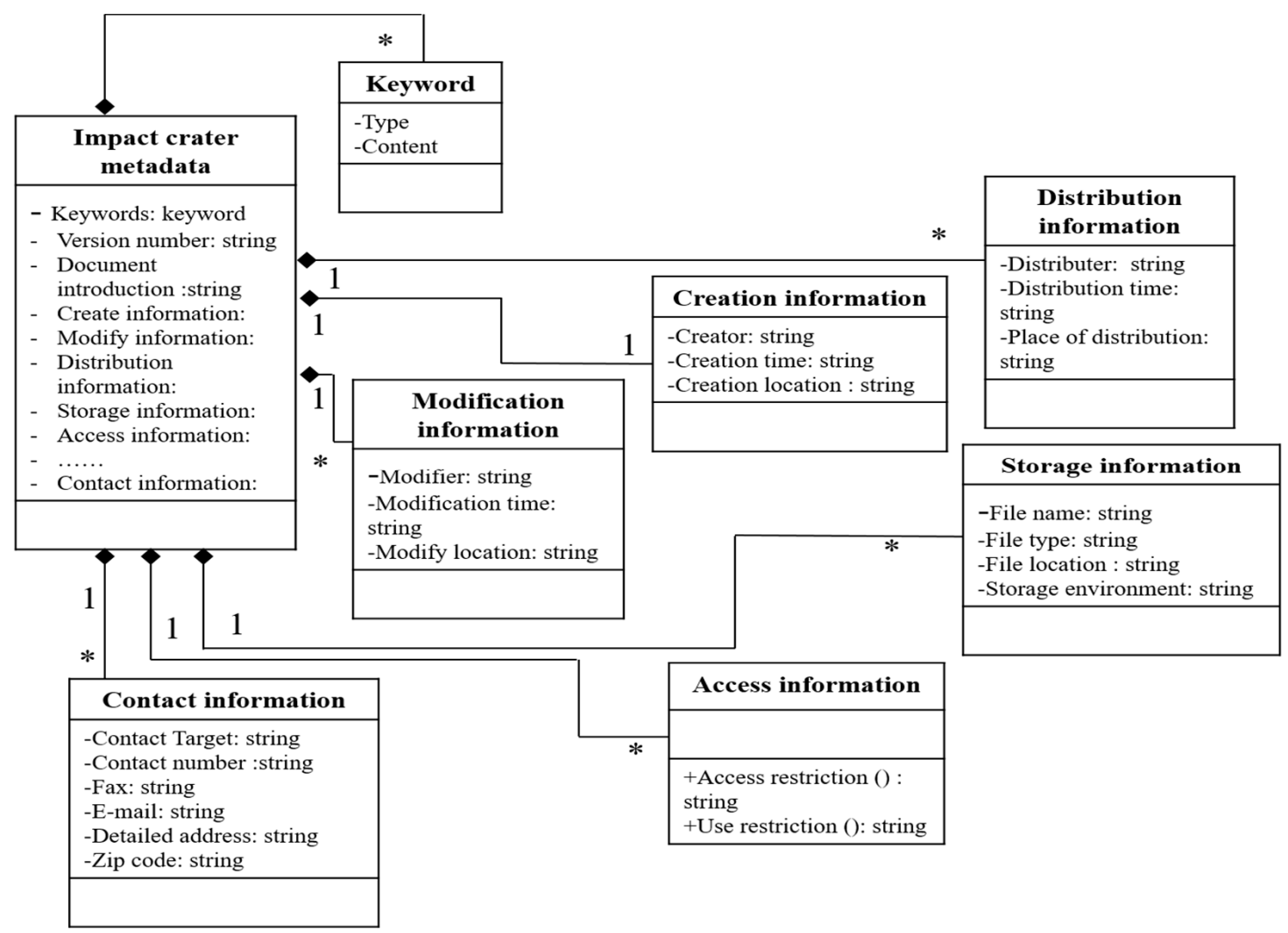

Figure 13. UML for the metadata organisation of descriptive indices.

\subsection{Content Organisation of Descriptive Indices}

The composition of impact crater elements and the classification of craters are considered when designing the content organisation for descriptive indices. The index content is organised by considering components from top to bottom, from groups to individuals, and from individuals to individuals. The data are organised at three levels: crater basic information, classification information, and index information. A detailed UML diagram is shown in Figure 14. 


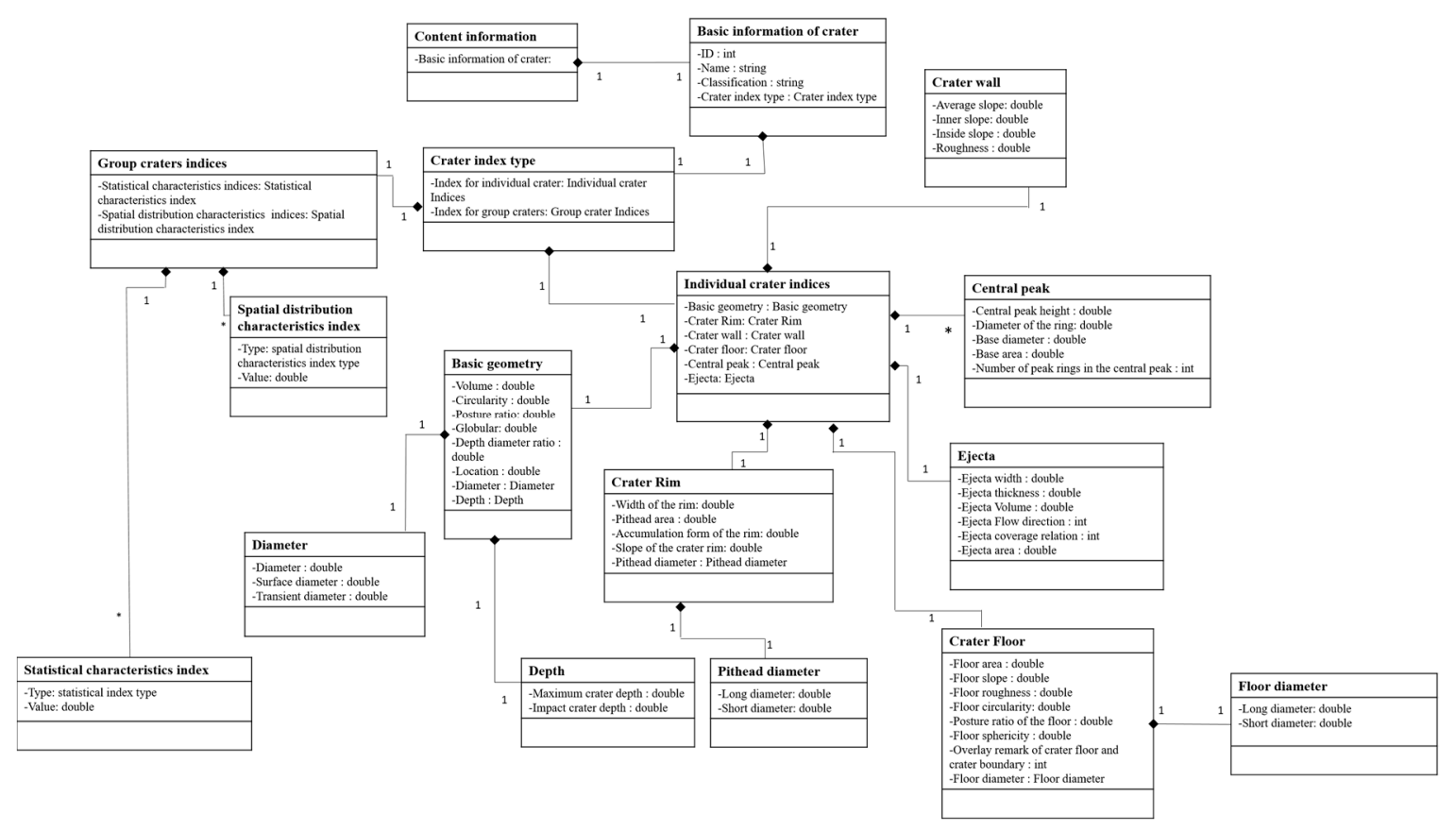

Figure 14. UML for the content organisation of descriptive indices.

\subsection{Description Standard for Descriptive Indices}

For a structured representation, we establish a description standard for impact craters referred by the design idea of the Content Standard for Digital Geospatial Metadata (CSDGM) v2.0 by the Federal Geographic Data Committee (FGDC). This description standard aims to provide a standardised data presentation method for the descriptive indices of lunar impact craters, to allow researchers to analyse, summarise, and organise crater indices in a structural way, and to eventually provide a theoretical basis for crater index studies. The standard can be downloaded from: http:/ /geomodeling.njnu.edu. $\mathrm{cn} /$ DesStandard4Lunar/download.html.

Figure 15a,b shows the XML scheme used to represent the sub-elements of basic geometry of an individual crater and a crater group, respectively.

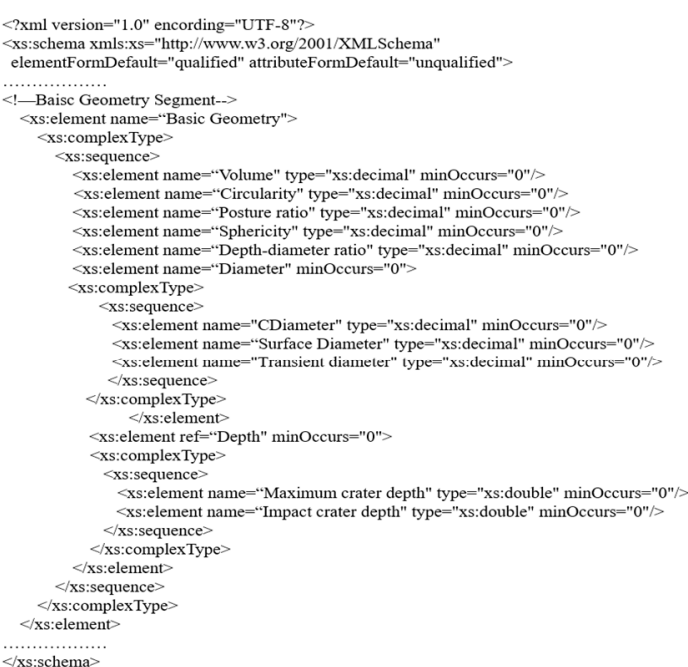

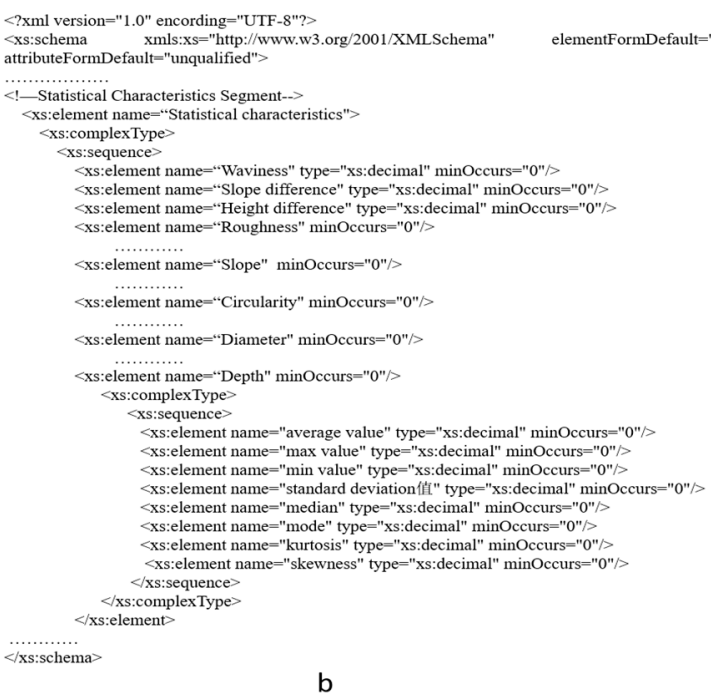

b

Figure 15. Fragments of the XML scheme for the usage of indices. (a) Basic Geometry; (b) Statistical characteristics. 


\section{Case Study and Application-Heterogeneity Analysis as an Example}

\subsection{Data Preparation}

In this study, DEM data with a resolution of $100 \mathrm{~m}$ from Lunar Reconnaissance Orbiter (LRO) was chosen as the main crater detection data source for further analysis. The projection of the DEM is EQUIRECTANGULAR_MOON except polar regions. The projection of the DEM is POLAR_STEREOGRAPHIC_MOON in polar regions.

\subsection{Detection of Lunar Impact Craters in Different Areas}

\subsubsection{Experimental Areas}

Experimental areas were selected based on different locations, morphological characteristics, and geological ages. Accordingly, six typical study areas were selected, as shown in Figure 16.

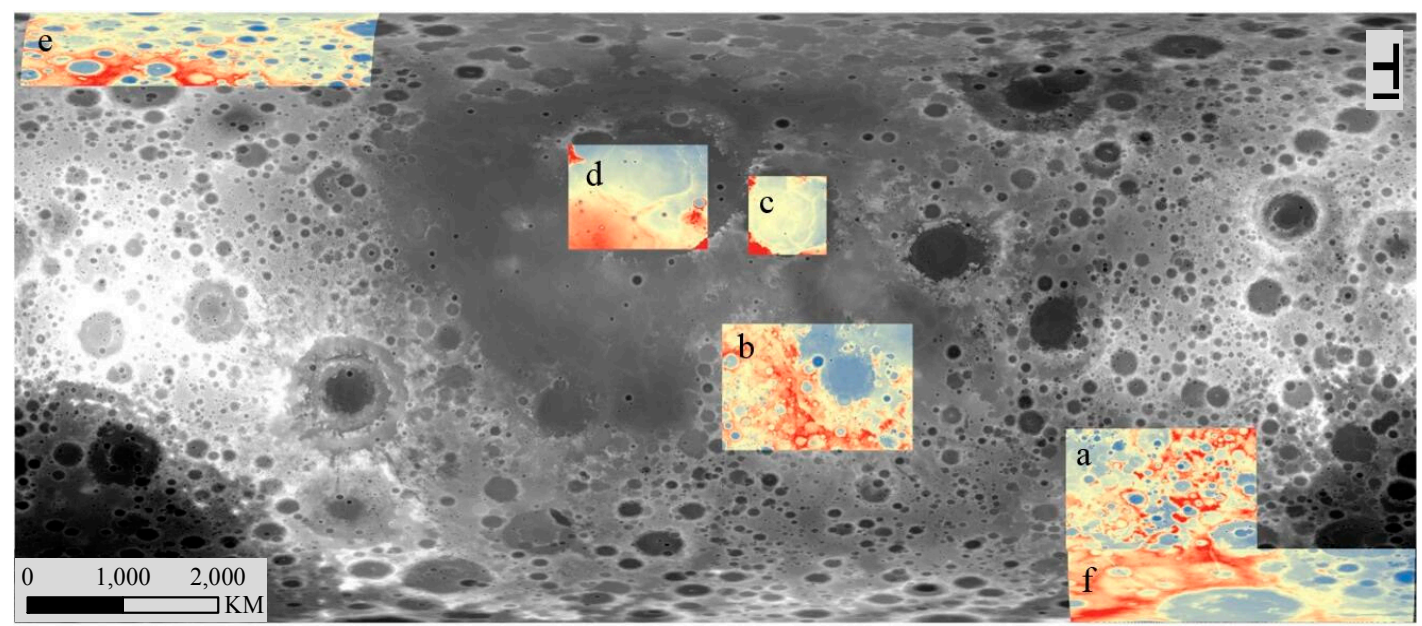

Figure 16. Experimental areas for the heterogeneity analysis case study. These areas are located in: (a) Highland (far side); (b) Highland (near side); (c) Mare Serenitatis; (d) Mare Imbrium; (e) North Pole; and (f) South Pole.

\subsubsection{Detection Methods and Results}

Based on $100 \mathrm{~m}$ resolution data from LRO, the boundaries of impact craters were manually extracted with the real boundaries. Here, only impact craters with a diameter of $500 \mathrm{~m}$ or more were identified for analysis, and smaller craters were omitted.

As shown in Figure 17, the green lines represent identified impact craters with a diameter of $500 \mathrm{~m}$ or more.

We detected the green lines as the boundaries of craters using ArcGIS. Firstly, we generated the aspect from the DEM, the hillshade generated from the DEM, and the curvature of the DEM. Secondly, with the curvature of the DEM, the line with the largest curvature in local was chosen as crater rims. Thirdly, for the craters whose curvature changes were not obvious, we used the aspect of the DEM to auxiliary judgment. Fourthly, if the curvature and aspect of the DEM were both not obvious, we used the hillshade of the DEM and slope of the DEM to detect the crater rims. It should be noted that these experiments demonstrate the capacity and usage of the proposed descriptive indices, and the precision can be improved with future improvements to the detection method. Figure 18 shows a part of the results (region D) of the detection methods that are described using the proposed indices, including Pithead area, Surface diameter, Impact crater depth, Depth-diameter Ratio, and Circularity. 


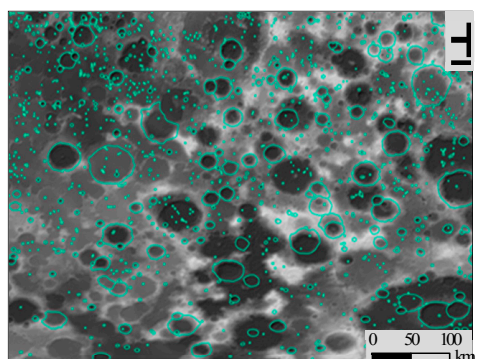

Region A in highland (far side) (R)

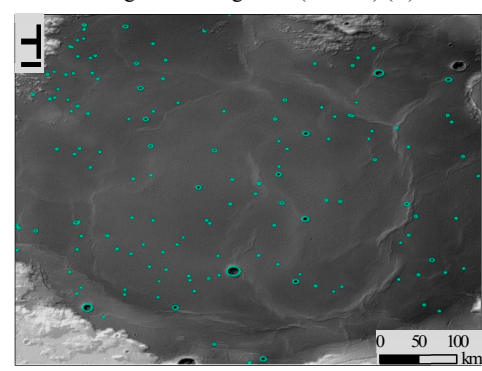

Region C in Mare Serenitatis

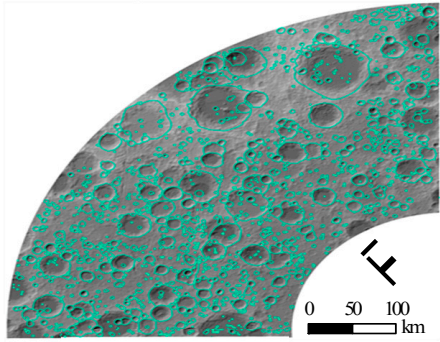

Region E in North Pole

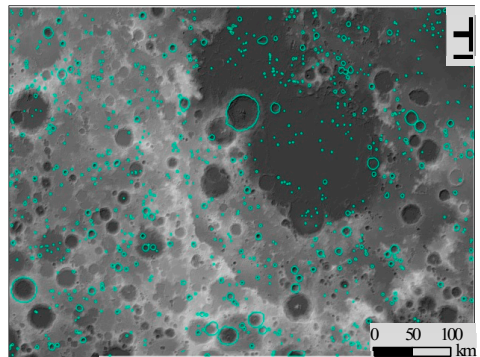

Region B in highland (near side)

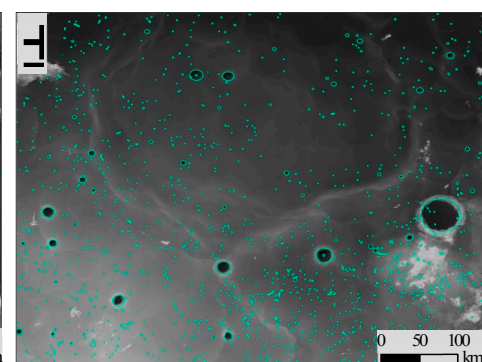

Region D in Mare Imbrium

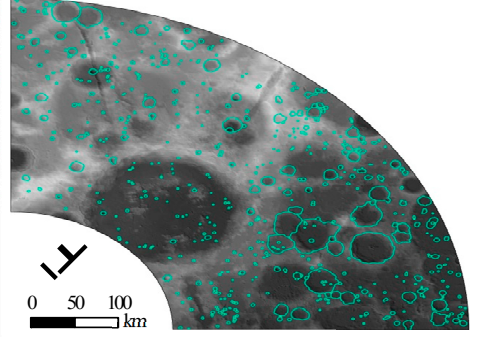

Region F in South Pole

Figure 17. Detection results of the heterogeneity analysis case study.

\begin{tabular}{|c|c|c|c|c|c|}
\hline Crater Number & Pithead area $\left(\mathrm{m}^{\wedge} 2\right)$ & Surface diameter $(\mathrm{m})$ & Impact crater depth (m) & Depth-diameter & Circularity \\
\hline 1 & 481177.5248 & 517.8063 & 70 & 0.1352 & 1.5116 \\
\hline 2 & 887661.248 & 709. 4094 & 36 & 0.0507 & 1.4986 \\
\hline 3 & 3798025.537 & 1887.0249 & 385 & 0.2040 & 1. 1653 \\
\hline 4 & 3962844.193 & 2136.4683 & 140 & 0.0655 & 1. 0514 \\
\hline 5 & 1183219.5 & 963.4037 & 135 & 0.1401 & 1.2740 \\
\hline 6 & 1823278.315 & 1505.6787 & 88 & 0.0584 & 1. 0119 \\
\hline 7 & 14832595.58 & 3626.0236 & 1232 & 0.3398 & 1. 1985 \\
\hline 8 & 2841750.055 & 1871. 3161 & 50 & 0.0267 & 1.0165 \\
\hline 9 & 2041755.849 & 1480.3553 & 53 & 0.0358 & 1.0892 \\
\hline 10 & 3191258.623 & 1996. 7974 & 55 & 0.0275 & 1.0095 \\
\hline 11 & 2555305.369 & 1771.1365 & 75 & 0.0423 & 1.0184 \\
\hline 12 & 3154654.301 & 1974. 0934 & 94 & 0.0476 & 1.0152 \\
\hline 13 & 3696565.2 & 2132. 5752 & 56 & 0.0263 & 1. 0173 \\
\hline 14 & 2519314.899 & 1639. 5684 & 51 & 0.0311 & 1.0924 \\
\hline 15 & 4426688.466 & 2333.8130 & 89 & 0.0381 & 1.0173 \\
\hline 16 & 2414352.958 & 1723.6492 & 86 & 0.0499 & 1.0172 \\
\hline 17 & 6114259.54 & 2756.7460 & 133 & 0.0482 & 1.0121 \\
\hline 18 & 3270509.574 & 1944. 2598 & 265 & 0.1363 & 1.0496 \\
\hline 19 & 7858661.266 & 3090.7561 & 286 & 0.0925 & 1. 0234 \\
\hline 20 & 2837077.247 & 1851. 9957 & 63 & 0.0340 & 1.0262 \\
\hline 21 & 3033535.369 & 1941. 3591 & 88 & 0.0453 & 1.0123 \\
\hline 22 & 3173645.46 & 1921. 1802 & 82 & 0.0427 & 1.0463 \\
\hline 23 & 9903034.516 & 3529.0065 & 330 & 0.0935 & 1.0062 \\
\hline 24 & 7530695.965 & 2848.8154 & 177 & 0.0621 & 1. 0869 \\
\hline 25 & 3654129.244 & 2112.8099 & 97 & 0.0459 & 1.0209 \\
\hline 26 & 4939011. 297 & 2471. 4369 & 104 & 0.0421 & 1. 0147 \\
\hline 27 & 5414507.357 & 2593.8241 & 138 & 0.0532 & 1.0123 \\
\hline 28 & 3688403.434 & 2064.5935 & 369 & 0.1787 & 1.0496 \\
\hline 29 & 5545504.241 & 2522. 0569 & 323 & 0.1281 & 1. 0536 \\
\hline 30 & 5225144.859 & 2295. 3821 & 381 & 0.1660 & 1.1237 \\
\hline 31 & 28498292.88 & 5986.5167 & 1135 & 0.1896 & 1. 0062 \\
\hline 32 & 2627497.633 & 1809.1850 & 61 & 0.0337 & 1.0110 \\
\hline 33 & 5746126.9 & 2674.0755 & 213 & 0.0797 & 1.0115 \\
\hline
\end{tabular}

Figure 18. A section of the detection results in region $\mathrm{D}$ with its index description. 


\subsubsection{Usage of the Descriptive Indices and Further Heterogeneity Analyses}

Based on the proposed descriptive indices, heterogeneity analyses were performed for each study area using the statistical characteristic indices, and the results are shown in Tables 8-10. The case studies only illustrate the practicality of the indices, and the accuracy and precision of statistical results can be enhanced with more accurate data and precise extraction. The relevant statistical results can be used for further investigation of the differences between impact craters in different areas of the Moon.

Table 8. Heterogeneity of craters in different experimental areas using the depth-diameter ratio.

\begin{tabular}{cccccc}
\hline Sample Area & Number of Craters & Min Value & Max Value & Average Value & Standard Deviation \\
\hline Region A & 819 & 0.02308 & 0.35149 & 0.11307 & 0.05168 \\
Region B & 819 & 0.04566 & 0.32348 & 0.15212 & 0.05224 \\
Region C & 141 & 0.02744 & 0.20681 & 0.09379 & 0.04328 \\
Region D & 671 & 0.02045 & 0.39219 & 0.06989 & 0.04764 \\
Region E & 365 & 0.03890 & 0.30875 & 0.11768 & 0.04194 \\
Region F & 417 & 0.02735 & 0.25244 & 0.13519 & 0.04935 \\
\hline
\end{tabular}

From the above table, it can be seen that the largest average value of depth-diameter ratio is in Region $\mathrm{B}$, and the smallest average value is in Region D. For standard deviation, the largest value is in Region B, and the smallest is in Region E. That is to say, the difference of depth-diameter ratio in Region B is the most obvious.

Table 9. Heterogeneity of craters in different experimental areas using the circularity.

\begin{tabular}{cccccc}
\hline Sample Area & Number of Craters & Min Value & Max Value & Average Value & Standard Deviation \\
\hline Region A & 819 & 1.00540 & 1.93016 & 1.04264 & 0.04778 \\
Region B & 819 & 1.00431 & 1.62624 & 1.03160 & 0.04639 \\
Region C & 141 & 1.00027 & 1.27284 & 1.01533 & 0.02536 \\
Region D & 671 & 1.00303 & 1.51161 & 1.02453 & 0.04033 \\
Region E & 365 & 1.00027 & 1.35002 & 1.02718 & 0.02936 \\
Region F & 417 & 1.00089 & 1.43969 & 1.02432 & 0.04130 \\
\hline
\end{tabular}

From the above table, the largest value of circularity is in Region A, and the smallest is in Region C, in terms of the average value. For standard deviation, the largest value is in Region $\mathrm{A}$, and the smallest is in Region C. That is to say, the difference of depth-diameter ratio in Region A is the most obvious.

Table 10. Heterogeneity of craters in different experimental areas using the percentage of crater area and density.

\begin{tabular}{|c|c|c|c|c|c|}
\hline Sample Area & $\begin{array}{l}\text { Number } \\
\text { of Craters }\end{array}$ & $\begin{array}{l}\text { Total Pithead } \\
\text { Area of Crater } \\
\text { Groups }\left(\mathbf{k m}^{2}\right)\end{array}$ & $\begin{array}{l}\text { Total Region } \\
\text { Area }\left(\mathbf{k m}^{2}\right)\end{array}$ & $\begin{array}{l}\text { Percent of } \\
\text { Crater Area }\end{array}$ & $\begin{array}{c}\text { Density } \\
\left(\text { Count } / \mathrm{km}^{2}\right)\end{array}$ \\
\hline Region A & 819 & $62,871.17$ & $1,408,337.50$ & $4.46 \%$ & 0.000582 \\
\hline Region B & 819 & $58,848.77$ & $1,472,877.53$ & $4.00 \%$ & 0.000556 \\
\hline Region C & 141 & 1750.32 & $320,977.41$ & $0.55 \%$ & 0.000439 \\
\hline Region D & 671 & 9049.93 & $896,390.34$ & $1.01 \%$ & 0.000749 \\
\hline Region E & 365 & $16,100.20$ & $590,822.81$ & $2.73 \%$ & 0.000618 \\
\hline Region F & 417 & $29,448.67$ & $585,408.36$ & $5.03 \%$ & 0.000712 \\
\hline
\end{tabular}

From the above table, the largest value of density is in Region D, and the smallest is in Region C, likely due to heavier impact as compared to other regions.

Although the above heterogeneity analysis is related simply based on these indices at the current stage, with specific knowledge related to the moon, e.g., the formation ages of the lunar craters, 
and surface materials, a better understanding of the moon can be acquired and new ideas can be explored in different regions.

\section{Conclusions and Future Research}

This study proposes a descriptive indices system for lunar craters and their morphology based on their morphological characteristics and spatial structures. Examples show that the proposed systematic indices can be used to give a clear description of the geometrical morphology of lunar craters. It will also provide a basis for in-depth studies on the morphological structure, classification, and evolution of lunar craters, as well as an insight into related research fields, such as automatic detection of impact craters (e.g., [57]), estimations of the geological age of the lunar surface, determining the thickness of the lunar regolith, and correcting landing locations for the soft landing of probes.

However, there are some issues with the proposed descriptive indices system that must be addressed in the future:

(1) The morphology of impact craters is complicated. The descriptive index system proposed here cannot cover all crater characteristics; e.g., the complex relationships between different craters. Future research may be required to make the system more complete.

(2) For some descriptive indices, e.g., ejecta flow directions and accumulation form of the rim, there are no well-established and quantified calculation methods. In the future, specific calculation methods may be proposed for improved quantification of these indices.

(3) The combination of individual indices to express the complex morphological lunar surface is still under exploration. This should be developed to reflect and contribute to research related to the formation mechanisms of impact craters, their evolution and development, and the performance of heterogeneity analyses.

Acknowledgments: We appreciate the detailed suggestions and constructive comments from the editor and the anonymous reviewers. This research was supported by the National Natural Science Foundation of China (No. 41371424), and the Priority Academic Program Development of Jiangsu Higher Education Institutions (164320H116).

Author Contributions: The original idea was proposed by Min Chen and Mengling Lei; the manuscript was written by Min Chen, Mengling Lei, and Danyang Liu; the experiments were conducted by Hao Zhao, Yi Zhou, and Kejian Qian. All authors have read and approved the final manuscript.

Conflicts of Interest: The authors declare no conflict of interest.

\section{References}

1. Jaumann, R.; Hiesinger, H.; Anand, M.; Crawford, I.A.; Wagner, R.; Sohl, F.; Jolliff, B.L.; Scholten, F.; Knapmeyer, M.; Hoffmann, H.; et al. Geology, geochemistry, and geophysics of the Moon: Status of current understanding. Planet. Space Sci. 2012, 74, 15-41. [CrossRef]

2. Ouyang, Z.Y. Introduction to Lunar Science; China Space Press: Beijing, China, 2005.

3. Ouyang, Z.Y. Scientific objectives of Chinese lunar exploration project and development strategy. Adv. Earth Sci. 2004, 19, 351-358.

4. Hörz, F.; Grieve, R.; Heiken, G.; Spudis, P.; Binder, A. Lunar surface processes. In Lunar Sourcebook: A User's Guide to the Moon; Cambridge University: Cambridge, UK, 1991; pp. 61-120.

5. Knight, C.; Butler, A. Who Built the Moon; Watkins: Winona, MN, USA, 2006.

6. Heiken, G.H.; Vaniman, D.T.; French, B.M. Lunar Sourcebook: A User's Guide to the Moon; Cambridge University Press: London, UK, 1991.

7. Eckart, P. The Lunar Base Handbook; McGraw-Hill Higher Education: New York, NY, USA, 1999.

8. Neukum, G.; Ivanov, B.A. Crater size distributions and impact probabilities on earth from lunar, terrestrial-planet, and asteroid cratering data. In Hazards Due to Comets and Asteroids; Gehrels, T., Matthews, S., Schumann, A.M., Eds.; University of Arizona Press: Tucson, AZ, USA, 1994.

9. Spudis, P. The Geology of Multi-Ring Impact Basins; Cambridge University Press: Cambridge, UK, 2005. 
10. Zhou, Z.P.; Cheng, W.M.; Zhou, C.H.; Zhao, S.M.; Xia, Y. Characteristic analysis of the lunar surface and automatically extracting of the lunar morphology based on CE-1. Chin. Sci. Bull. 2011, 56, 18-26. [CrossRef]

11. International Astronomical Union. 2012. Available online: http://planetarynames.wr.usgs.gov/Page/ MOON/target (accessed on 4 November 2017).

12. Oberbeck, V.R.; Quaide, W.L. Genetic implication of lunar regolith thickness variations. Icarus 1968, 9, 446-465. [CrossRef]

13. Stöffler, D.; Ryder, G.; Ivanov, B.A.; Artemieva, N.A.; Cintala, M.J.; Grieve, R.A.F. Cratering history and lunar chronology. Rev. Mineral. Geochem. 2006, 60, 519-596. [CrossRef]

14. He, S.J.; Chen, J.P.; Ke, K. The morphological classification and distribution characteristics of the craters in the LQ-4 Area. Front. Earth Sci. 2012, 19, 83-89.

15. Baldwin, R.B. The Face of the Moon; University of Chicago Press: Chicago, IL, USA, 1949.

16. Fieder, G. Lunar Geology; DuFour Editions: Chester Springs, PA, USA, 1967.

17. Nakano, F. The Moon and Its Observation; Kouseisha Kouseikaku Co., Ltd.: Shinjuku, Japan, 1970.

18. Wood, C.A.; Anderson, L. New morphometric data for fresh lunar craters. In Proceedings of the 9th Lunar and Planetary Science Conference, Houston, TX, USA, 13-17 March 1978; Pergamon Press, Inc.: New York, NY, USA, 1978; pp. 3669-3689.

19. Neukum, G.; Konig, B.; Arkani-Hamed, J. A study of lunar impact crater size-distributions. Moon 1975, $12,201$. [CrossRef]

20. Pike, R.J. Size-dependence in the shape of fresh impact craters on the moon. In Impact and Explosion Cratering: Planetary and Terrestrial Implications, Proceedings of the Symposium on Planetary Cratering Mechanics, Flagstaff, AZ, USA, 13-17 September 1976; Pergamon Press, Inc.: New York, NY, USA, 1977; pp. 489-509.

21. Kneissl, T.; Gasselt, S.V.; Neukum, G. Map-projection-independent crater size-frequency determination in GIS environments-New software tool for ArcGIS. Planet. Space Sci. 2011, 59, 1243-1254. [CrossRef]

22. Head, J.W. Lunar volcanism in space and time. Rev. Geophys. Space Phys. 1976, 14, 265-300. [CrossRef]

23. Schultz, P.H. Moon Morphology; University of Texas Press: Austin, TX, USA, 1976.

24. Pike, R.J.; Spudis, P.D. Basin-ring spacing on the Moon, Mercury, and Mars. Earth Moon Planets 1987, 39, 129-194. [CrossRef]

25. Hiesinger, H.; Head, J.W. New Views of Lunar Geoscience: An Introduction and Overview. Rev. Mineral. Geochem. 2006, 60, 1-81. [CrossRef]

26. Pike, R.J. Depth/diameter relations of fresh lunar craters: Revision from spacecraft data. Geophys. Res. Lett. 1974, 1, 291-294. [CrossRef]

27. Pike, R.J. Formation of complex impact craters: Evidence from Mars and other planets. Icarcus 1980, 43, 1-19. [CrossRef]

28. Moutsoulas, M.; Preka, P. Morphological characteristics of lunar craters with small depth/diameter ratio I. Earth Moon Planets 1979, 21, 299-305. [CrossRef]

29. Moutsoulas, M.; Preka, P. Morphological characteristics of lunar craters with small depth/diameter ratio II. Earth Moon Planets 1980, 23, 113-126.

30. Head, J.W. Lava flooding of ancient planetary crusts: Geometry, thickness, and volumes of flooded lunar impact basins. Moon Planets 1982, 26, 61-88. [CrossRef]

31. Head, J.W.; Wilson, L. Lunar mare volcanism: Stratigraphy, eruption conditions, and the evolution of secondary crusts. Geochim. Cosmochim. Acta 1992, 56, 2155-2175. [CrossRef]

32. Ouyang, Z.Y.; Zou, Y.L.; Li, C.L.; Liu, J.Z. Prospect of exploration and utilization of some lunar resources. Earth Sci. J. China Univ. Geosci. 2002, 27, 498-503.

33. Zhang, X.Q.; Xia, X.W. Research dynamics of lunar crater. Progress Geophys. 2008, 6, 1797-1801.

34. Shoemaker, E.M. Preliminary analysis of the fine structure of the lunar surface in Mare Cognitum. Nat. Lunar Surf. 1965, 1, 23.

35. McEwen, A.S.; Bierhaus, E.B. The importance of secondary cratering to age constraints on planetary surfaces. Ann. Rev. Earth Planet. Sci. 2006, 34, 535-567. [CrossRef]

36. Yue, S.S.; He, L.; Wen, Y.N.; Lu, G.N.; Lin, H. Shape characteristics-based extraction of lunar impact craters: Using DEM from the Chang'E-1 satellite as a data source. Ann. GIS 2013, 19, 53-62. [CrossRef]

37. Florensky, C.P.; Basilevsky, A.T.; Grebennik, N.N. The relationship between lunar crater morphology and crater size. Earth Moon Planets 1976, 16, 59-70. [CrossRef] 
38. Head, J.W.; Fassett, C.I.; Kadish, S.J.; Smith, D.E.; Zuber, M.T.; Neumann, G.A.; Mazarico, E. Global distribution of large lunar craters: Implications for resurfacing and impactor populations. Science 2010, 329, 1504-1507. [CrossRef] [PubMed]

39. Michael, G.G.; Neukum, G. Planetary surface dating from crater size-frequency distribution measurements: Partial resurfacing events and statistical age uncertainty. Earth Planet. Sci. Lett. 2010, 294, 223-229. [CrossRef]

40. Zhao, J.N.; Huang, J.; Long, X.; Qiao, L.; Wang, J.; Hu, S.Y. Crater Size-Frequency Distribution Measurements and Age Determination of Sinus Iridum. Earth Sci. 2013, 38, 351-361.

41. Bart, G.D. Lunar Surface Geology from Analysis of Impact Craters and Their Ejecta. Ph.D. Thesis, University of Arizona, Tucson, AZ, USA, 2007.

42. Bart, G.D.; Melosh, H.J. Distributions of boulders ejected from lunar craters. Icarus 2010, 209, $337-357$. [CrossRef]

43. Chen, M.; Lin, H.; Wen, Y.N.; He, L.; Hu, M.Y. Sino-VirtualMoon: A 3D web platform using Chang'e-1 data for collaborative research. Planet. Space Sci. 2012, 65, 130-136. [CrossRef]

44. Chen, M.; Lin, H.; Wen, Y.N.; He, L.; Hu, M.Y. Construction of a virtual lunar environment platform. Int. J. Digit. Earth 2013, 6, 469-482. [CrossRef]

45. Greene, M.T. Alfred Wegener and the origin of lunar craters. Earth Sci. Hist. 1998, 17, 111-138. [CrossRef]

46. Melosh, H.J.; Ivanov, B.A. Impact crater collapse. Ann. Rev. Earth Planet. Sci. 1999, 27, 385-415. [CrossRef]

47. Martellato, E.; Foing, B.H.; Benkhoff, J. Numerical modelling of impact crater formation associated with isolated lunar skylight candidates on lave tubes. Planet. Space Sci. 2013, 86, 33-44. [CrossRef]

48. Lunar and Planetary Institute. Available online: https://www.lpi.usra.edu/exploration/education/ hsResearch/crateringLab/lab/part1/background/ (accessed on 26 December 2017).

49. Favalli, M.; Karátson, D.; Mazzarini, F. Morphometry of scoria cones located on a volcanoflank: A case study from Mt. Et-na (Italy), based on high-resolution LiDAR data. J. Volcanol. Geotherm. Res. 2009, 186, 320-330. [CrossRef]

50. Pike, R.J. Apparent depth/apparent diameter relation for lunar craters. In Proceedings of the 8th Lunar and Planetary Science Conference, Houston, TX, USA, 14-18 March 1977; pp. 3427-3436.

51. Pike, R.J. Volcanoes on the inner planets: Some preliminary comparisons of gross topography. In Proceedings of the 9th Lunar and Planetary Science Conference, Houston, TX, USA, 13-17 March 1978; pp. 3239-3273.

52. Nasa Science Earth's Moon Beta. Available online: https://www.nasa.gov/moon (accessed on 26 December 2017).

53. Hale, W.; Head, J.W. Central peaks in lunar craters-morphology and morphometry. In Proceedings of the 10th Lunar and Planetary Science Conference, Houston, TX, USA, 19-23 March 1979; pp. 2623-2633.

54. Oberbeck, V.R.; Morrison, R.H.; Hörz, F. Smooth plains and continuous ejecta de-posits of craters and basin. In Proceedings of the 5th Lunar and Planetary Science Conference, Houston, TX, USA, 18-22 March 1974; pp. 111-136.

55. Kring, D.A. The dimensions of the Chicxulub impact crater and impact melt sheet. J. Geophys. Res. Planet. 1995, 100, 16979-16989. [CrossRef]

56. Zhou, Q.M.; Liu, X.J. Digital Terrain Analysis; Science Press: Beijing, China, 2006.

57. Liu, D.Y.; Chen, M.; Qian, K.J.; Lei, M.L.; Zhou, Y. Boundary Detection of Dispersal Impact Craters Based on Morphological Characteristics Using Lunar Digital Elevation Model. IEEE J. Sel. Top. Appl. Earth Obs. Remote Sens. 2017, 10, 5632-5646. [CrossRef]

(C) 2017 by the authors. Licensee MDPI, Basel, Switzerland. This article is an open access article distributed under the terms and conditions of the Creative Commons Attribution (CC BY) license (http://creativecommons.org/licenses/by/4.0/). 